\title{
1 Analytical and numerical prediction of the bending behaviour of textile reinforced
}

concrete sandwich beams

Isabella Giorgia Colombo, Matteo Colombo, Marco di Prisco and Farhang Pouyaei

Politecnico di Milano - Department of Civil and Environmental Engineering

Phone: $+390223998790 \quad$ Fax: $\quad+390223998771 \quad$ URL: $\quad$ www. polimi.it

@ isabellagiorgia.colombo@polimi.it; matteo.colombo@polimi.it; marco.diprisco@polimi.it; farhangpye@gmail.com

\section{Abstract}

This paper concerns the investigation of the behaviour of sandwich beams previously tested in four point bending through analytical and numerical models. Modelling is a fundamental resource to predict the mechanical response of the element and to investigate the mechanisms that act during the evolution of the test.

The sandwich beams here taken into account are characterised by external textile reinforced concrete (TRC) layers and an insulation material (expanded polystyrene, EPS) able to transfer shear stresses. Bond between the layers is obtained during production thanks to an in-pressure casting technique, and no particular device is used in order to transfer shear stresses between the layers. Two beam slenderness values are taken into account.

An analytical and a numerical approach have been used in order to predict the experimental behaviour: concerning the analytical approach, a model based on the Stamm and Witte sandwich theory has been developed including material nonlinearity; concerning the numerical analysis, a finite element (FE) model has been built in ABAQUS including material and geometry non-linearity. The assumption of perfect bond is used in both cases.

The non-linear analytical and finite element models have been validated, as a good agreement with experimental results has been achieved. The experimental identification of material parameters - TRC in tension, mortar in compression and EPS in tension, compression and shear - is crucial for the definition of proper constitutive laws for the models and is here presented and discussed. For both approaches, the assumptions of modelling TRC in bending as homogeneous and assuming perfect bond between TRC and EPS (even when behaviour becomes highly non-linear) have been proved to be reliable. Analytical and FEM results show that EPS non-linear behaviour and TRC membrane and bending behaviour govern the response. The FE analysis also highlights the mechanisms involved in specimen failure.

Textile reinforced concrete (TRC); sandwich beam; four-point bending test; non-linear analytical model; finite element method. 


\section{Introduction}

Since the 1940s, sandwich constructions have been used primarily in the aircraft industry and later in the missile and spacecraft structures [1]. Starting from the 1960s, the sandwich solution was applied in other fields, including buildings; a worldwide boom in prefabricated building elements favoured the diffusion of these sandwich products [2]. In particular, panels characterised by both the inner and the outer faces formed of metal sheets that act compositely with a relatively low strength core (with suitable insulating and stiffening properties) are largely diffused. For this kind of panel, the bond between components can be obtained through a line forming process, the use of adhesive or through mechanical fastenings. According to Davies [2], these sandwich solutions are designed in such a way that they act as a composite load-bearing unit for the expected service life.

In the residential and commercial building industry, in Europe and North America, the use of pre-cast R/C cladding sandwich panels is largely diffused; both the structural and the insulating potential of these wall elements are exploited [3]. Generally, two external R/C layers and an inner insulation layer characterise these wall panels. Various types of shear connectors are used to link the external concrete faces; depending on their stiffness and strength, the panel behaves as non-composite, partially-composite or fully-composite $[4,5,6]$. The weight is considerably higher with respect to panels characterised by metallic faces; in fact, the thickness of each concrete layer has been reduced to $40 \mathrm{~mm}$ only recently [3]. Hegger and Horstmann [7] proposed wall and floor sandwich panels in which both the concrete layers are made of textile reinforced concrete (TRC). This solution allowed the researchers to obtain a lightweight precast product full of design and finishing capabilities, free from corrosion problems, and characterised by good durability. The introduction of shear connectors allowed for adequate and durable sandwich action [8]. Further recent research proposed sandwich elements with advanced cementitious composite faces connected by means of adhesive bond to the insulating material without using any connector $[9,10,11,12,13,14]$.

A model able to reproduce the panel behaviour is crucial for the design of this kind of solution. In literature, analytical and numerical models are proposed to predict the bending behaviour of sandwich elements.

The simplest analytical model that can be applied to a sandwich beam is based on the plane section assumption. However, this approach is not suitable to predict the real response of the sandwich, as the shear deformability of the core generally plays a key role and it is not taken into account. Stamm and Witte [15] proposed an analytical model for sandwich beams, which accounts for the shear deformability of the core and considers the bending stiffness of the outer layers, that cannot be neglected. The model is based on the formulation previously proposed by Plantema [16]. In this model linear elastic materials are assumed. Shams et al. [17] implemented the Stamm and Witte analytical model to account for the non-linear behaviour of the materials. As the equations in [15] are solved for constant bending and axial stiffness, to avoid solving the differential equations with a stiffness function, the authors propose constant average stiffness values for the whole 
length of the beam. Two ways to compute the overall stiffness are proposed by the authors: weighting the beam local stiffness basing on the deflection or basing on the internal actions (e.g. bending moment). By investigating several TRC sandwich panels (characterised by different reinforcement and slenderness), the authors could state that the average beam stiffness, weighted on the deflection, accurately assesses the load-deflection behaviour taking into account the cracking of the concrete faces. The model used for deriving the shear stiffness of the core is described in [18].

In finite element analysis, when accounting for material non-linearity, TRC could be modelled considering the material as homogeneous [12] or discretizing the fabric as a grid reinforcement embedded in the matrix [19, 20, 21]. Larrinaga et al. [19] demonstrated that the assumption of rigid fabric-matrix interface is sufficient in order to estimate the global behaviour of the specimens with good accuracy. In the ABAQUS environment, some authors [22, 23] modelled foam materials through crushable foam model with volumetric hardening. In particular, concerning polystyrene foam, MassoMoreu and Mills [22] modelled extruded polystyrene (XPS) using truncated pyramidal shapes subjected to impact testing which led to a good prediction of the experimental results. Moreover, Ozturk and Anlas [23] modelled expanded polystyrene foam (EPS) under multiple compressive loading and unloading and demonstrated that it is possible to predict the force-displacement curve accurately for the first loading, while the numerical results do not match the experimental ones in case of unloading and reloading.

The present research is developed in the framework of a European project [24] concerning the energy retrofitting of existing buildings. A multi-layer precast panel $1.5 \mathrm{~m}$ wide and $3.3 \mathrm{~m}$ high, fastened to the existing façade through four punctual connectors, is proposed for the application on existing buildings; it is characterised by an inner insulation layer in expanded polystyrene (EPS, $100 \mathrm{~mm}$ thick) and by two outer faces in textile reinforced concrete (10 mm thick). EPS is used to transfer shear stresses between the two external TRC faces, thus preventing thermal bridges due to the presence of connectors. Few connectors are embedded in the full-scale panel to prevent the detachment in extreme loading conditions.

Specific investigations on durability of the interface between the external layer and EPS foam in case of freezing and thawing cycles have shown a reduction of the overall ductility [25].

Previous tests were performed on sandwich beams. The results of this campaign, deeply discussed in [26], underline the significant role played by the tangential non-linear behaviour of the EPS foam on the composite panel behaviour and allow a deeper understanding of the failure mechanisms, when different shear slenderness are considered. These experimental results are used as a reliable benchmark for the analytical and numerical models discussed in the present paper. 


\section{Reference experimental campaign and mechanical characterisation of materials}

\subsection{Reference experimental campaign}

The experimental results, taken as a reference in the paper, concern tests performed according to a four-point loading scheme on $550 \times 150 \mathrm{~mm}^{2}$ (“deep") and 1200 x $300 \mathrm{~mm}^{2}$ ("slender") sandwich beams. The test set-up is shown in Figure 1. Beams are characterised by two $10 \mathrm{~mm}$ thick external layers made of textile reinforced concrete (TRC) connected by a $100 \mathrm{~mm}$ thick insulation layer of expanded polystyrene foam (EPS250). All the details concerning the experimental campaign and test results can be found in [26], in which deep beams are named "small" (specimens S1, S2, S3 and S4) and slender beams are named "big" (specimens B1, B2, B3 and B4). In this paper, the same notation is used to identify the specimens.
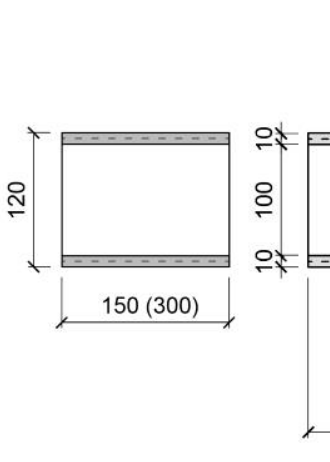

Fig. 1 Deep and slender sandwich beam geometry and test set-up (in mm). Values in parentheses represent slender specimens.

Sandwich beams are produced adopting an in-pressure casting technique in order to minimise the voids in the mortar and to enhance the bond between TRC layers and EPS, also because only the insulating material is used to transfer the shear between the external TRC layers [26].

From the experimental results emerged that a large ductility was experienced by both deep and slender specimens; this ductility was achieved thanks to the multi-cracking of both TRC layers and the large compressive plastic strain experienced by the EPS core. The fabric position in TRC layer thickness affected the multi-cracking pattern, but not the global response. Hence, it has to be regarded at Serviceability Limit State, in which crack opening needs to be controlled, rather than at Ultimate Limit State, in which the ultimate bearing capacities is accounted for. Beams behaved as partially composite sandwich and the global non-linear response was strongly driven by the EPS plastic compressive strains. The failure was due to the tensile failure of TRC for deep specimens and to the EPS brittle cracking in the case of slender beams. Moreover, when the slenderness was higher, the mono-dimensional beam assumption seemed reliable, while not negligible strains in the load direction were registered in the case of deep beams, denoting a two dimensional behaviour of the samples. 
The analytical and numerical models shown in this paper allow further investigating the behaviour of deep and slender beams, in order to exactly understand the failure mechanism involved during the progress of the test.

In sections 2.2 and 2.3, the mechanical characterisation of TRC and EPS adopted for the sandwich production is provided.

\subsection{Textile reinforced concrete: uniaxial tension and bending}

TRC is obtained by reinforcing a high strength fine grain mortar with an alkali-resistant glass fabric, manufactured by means of a leno-weave technique and coated with a water resin based on styrene butadiene rubber (SBR).

The fabric used as reinforcement, whose geometrical and mechanical characteristics are collected in [26], is characterised by a nominal strength in the warp direction of $820 \mathrm{MPa}$ (computed on the equivalent cross-sectional area of the glass reinforcement).

The cementitious matrix used is characterised by a water to binder ratio equal to 0.225 and by a superplasticiser to cement ratio equal to $9.3 \%$. The maximum aggregate size selected is equal to $1 \mathrm{~mm}$. These properties guarantee a high flow capability and, hence, a good bond between matrix and fabric and the possibility to cast the mortar in pressure. 12 nominally identical specimens were used to measure the cubic compressive strength ( $\left.f_{c c}\right)$ according to EN 196-1 [27]. The average value is equal to $71.89 \mathrm{MPa}$ and the coefficient of variation is $9.13 \%$ of the average value.

In order to characterise the TRC layer behaviour in tension and bending, six nominally identical specimens with dimensions $400 \times 70 \times 10 \mathrm{~mm}^{3}$ were cast. These specimens were reinforced with one fabric placed in the middle of their thickness, with the warp aligned in the longitudinal direction.

Three specimens were tested in uniaxial tension, and three in bending. In both cases the tests were performed using an electromechanical press INSTRON 5867 with a maximum load capacity of $30 \mathrm{kN}$, imposing a constant cross-head displacement rate.

Concerning tensile tests on TRC, the same test apparatus and modalities described in [28] are used. The test results are shown in Figure 2(a) in terms of nominal stress $(\sigma=\mathrm{P} / \mathrm{A}$, with $\mathrm{P}=$ load and $\mathrm{A}=$ specimen cross section $)$ vs. nominal $\operatorname{strain}\left(\varepsilon=\delta_{\mathrm{LVDT}} / 1_{\mathrm{LVDT}}\right)$ curves.

Nominal strains are derived from a direct measure of axial displacement $\left(\delta_{\mathrm{LVDT}}\right)$ on the specimen during tensile tests: an inductive full bridge type transducer, with a nominal displacement equal to $10 \mathrm{~mm}$ and a gauge length (l $\left.l_{\text {LVDT }}\right)$ equal to about $200 \mathrm{~mm}$, is placed on the specimen. This choice allows the displacement measurement to not be affected by the relative sliding between specimen and clamping devices that may occur during tensile tests.

Bending tests on TRC specimens were performed according to a four-point bending scheme with a distance between the supports equal to $350 \mathrm{~mm}$ and a constant bending moment region $158 \mathrm{~mm}$ long. The tests were displacement controlled, with an imposed displacement rate of the machine cross-head equal to $1 \mathrm{e}-3 \mathrm{~mm} / \mathrm{sec}$. The test results are shown in Figure 2(b) in terms of load (P) vs. machine cross-head displacement $(\delta)$ curves. 


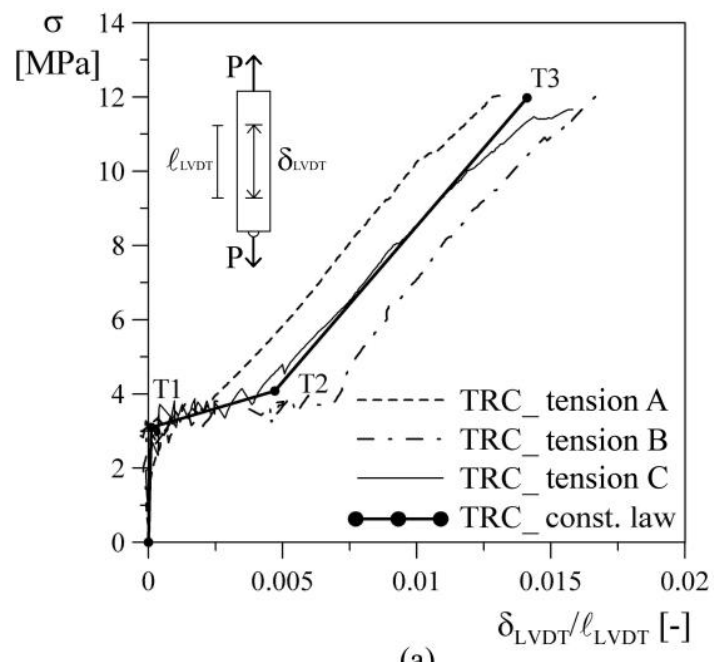

(a)

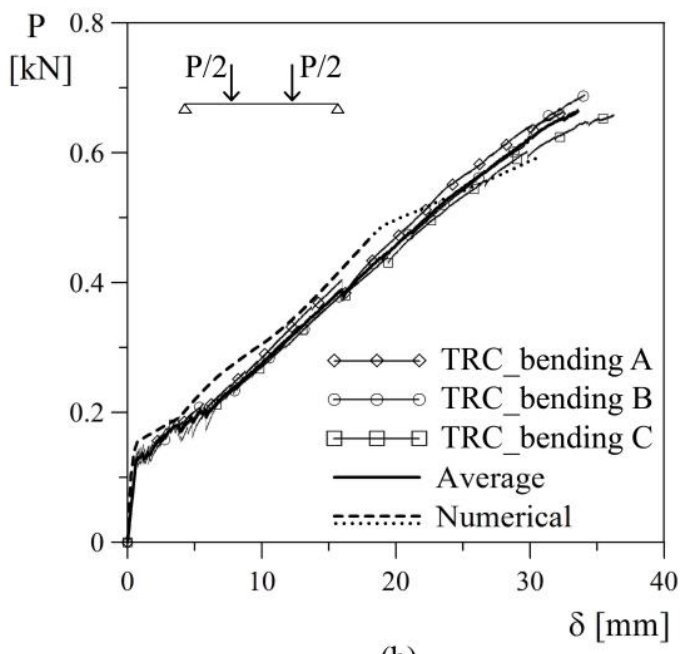

(b)

Fig. 2 TRC mechanical behaviour: results of tests in uniaxial tension (a) and bending (b). "TRC_const. law" curve and points "T1", "T2" and "T3" (subfigure a) are discussed in Sections 3.1 and 4.1, and "Numerical" curve (subfigure b) is discussed in Section 4.3.1.

\subsection{Expanded polystyrene: uniaxial compression, uniaxial tension and shear}

The expanded polystyrene foam used is commercially known as EPS250. According to EN 13163 [29], it is characterised by a compressive strength of $0.25 \mathrm{MPa}$ at a strain equal to $10 \%$.

Six nominally identical specimens with dimensions $100 \times 100 \times 150 \mathrm{~mm}^{3}$ were cut from a larger mat of EPS: three were tested in uniaxial compression and three in uniaxial tension by gluing their ends to the testing devices; all tests were performed using the same electromechanical press described above. The tests were displacement controlled by imposing a constant displacement rate of the machine cross-head equal to $1 \mathrm{e}-3 \mathrm{~mm} / \mathrm{sec}$. Test results are shown in Figure 3(a) and (b) respectively for tension and compression in terms of nominal stress $(\sigma=\mathrm{P} / \mathrm{A}$, with $\mathrm{P}=$ load and $\mathrm{A}=$ unloaded specimen cross section) versus nominal strain $(\varepsilon=\delta / \mathrm{h}$, with $\delta=$ top displacement and $\mathrm{h}=$ specimen height $)$ curves. The initial slope of the compressive $\sigma-\varepsilon$ curve, equal to $13.7 \mathrm{MPa}$, gives an estimation of the elastic modulus in compression. It is possible to observe that the compressive behaviour is elasto-hardening, while the uniaxial tensile behaviour is elastobrittle, with a higher strength in tension rather than in compression.

Three shear tests were performed on EPS specimens in order to determine the $\tau-\gamma$ shear constitutive law. A proper test set-up was adopted according to EN 12090 [30] following the prescriptions for the double test specimen assembly. The test results are plotted in Figure 3(c) in terms of nominal shear stress $(\tau=\mathrm{P} / 2 \mathrm{~A}$, with $\mathrm{P}=$ load and $\mathrm{A}=$ specimen crosssection) vs. nominal strain $(\gamma=\delta / t$, with $t=$ specimen thickness $)$ curves. The average maximum shear stress $(\bar{\tau})$ measured is equal to $0.16 \mathrm{MPa}$. An estimation of the shear modulus $\mathrm{G}$ can be defined as the initial slope of the experimental $\tau-\gamma$ curve and is equal to $5.04 \mathrm{MPa}$. 


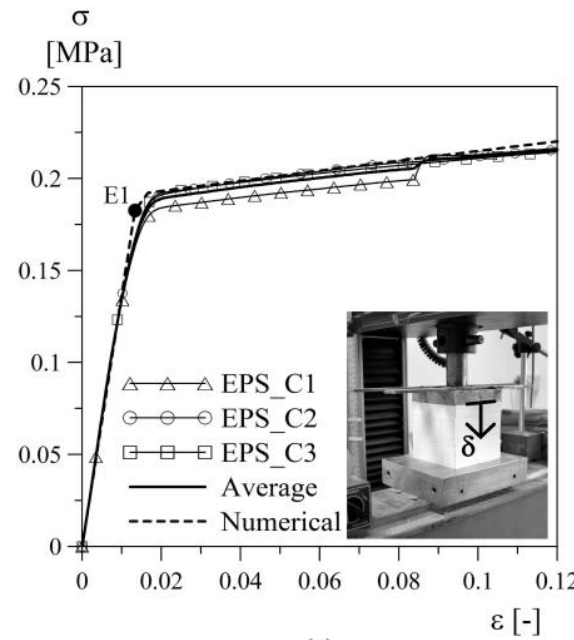

(a)

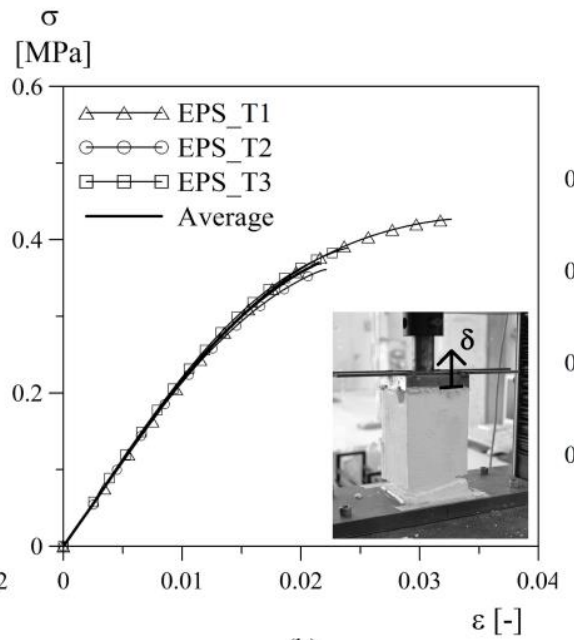

(b)

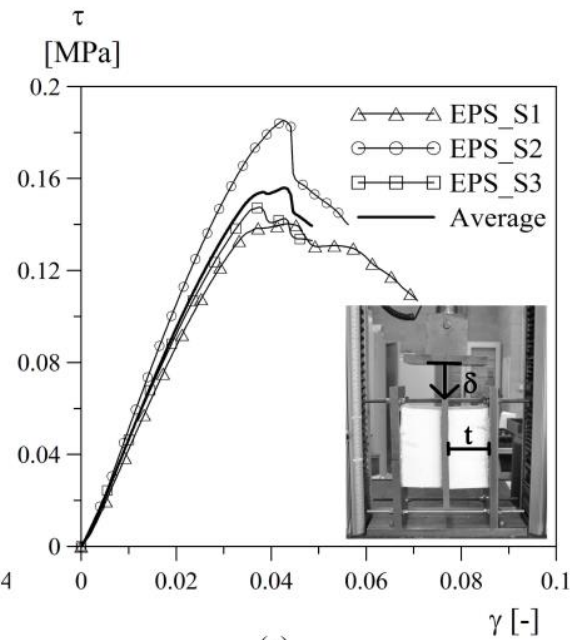

(c)

Fig. 3 EPS mechanical behaviour: results of tests in uniaxial compression (a), uniaxial tension (b) and shear (c).

"Numerical" curve and point "E1" (subfigure a) are discussed in Section 4.3.2.

\section{Analytical model for sandwich beams}

Classical Bernoulli beam theory cannot be used to predict the behaviour of a sandwich panel because of the large shear deformability of the composite. Stamm and Witte [15] proposed an analytical model to predict the behaviour of sandwich beams characterised by faces with no negligible bending stiffness if compared to the one of the whole beam: a previous model, whose solution is due to Plantema [16], was implemented by superimposing the local bending state of each external layer to the membrane state of stress of these outer layers due to sandwich global behaviour. The model is based on the following assumptions:

- the sandwich is characterised by faces with no negligible bending stiffness if compared to the one of the whole sandwich beam; for this reason the local bending state of each external layer is superimposed to the membrane state of stress of these outer layers due to sandwich global behaviour. The distribution of stresses considered is shown in Figure 4(a);

- $\quad$ the shear stiffness of the outer layers is large, hence their shear deformations $\gamma_{x z}^{\text {face }}$ can be neglected; the cross sections of the outer layers thus remain planar and perpendicular to the axis even after the deformation (Bernoulli hypothesis), see Figure 4(b);

- $\quad$ the core is soft if compared with the outer faces, hence $\sigma_{x}^{\text {core }}$ can be taken equal to zero, while $\tau_{x z}^{\text {core }}$ is constant (Figure 4(a));

- due to the shear deformation of the core, the total cross section of the sandwich beam is not plane, but it deforms to a broken line (as shown in Figure 4(b));

- $\quad$ the sandwich panel is calculated as a one-dimension structure, e.g. a beam; 
- $\quad$ small displacements and deformations are considered.

Stamm and Witte [15] provided the linear elastic solution of the problem considering Hooke's Law for both core and faces and taking into account different boundary and loading conditions.

An analytical solution has been implemented by the authors of the present paper following the same approach proposed by Shams et al. [17] in order to take into account the non-linear material behaviour in the Stamm and Witte model. The beam is divided into a finite number of elements with equal length and both axial and bending stiffness are assigned to each element accounting for non-linearity according to a secant stiffness approach. The differential equations of the Stamm and Witte model are solved by using constant and homogeneous equivalent stiffness values properly defined for each layer. A flow chart representing the steps of the analytical model is proposed in Figure 4(c). All symbols included in Figure 4 are collected in Table 1.
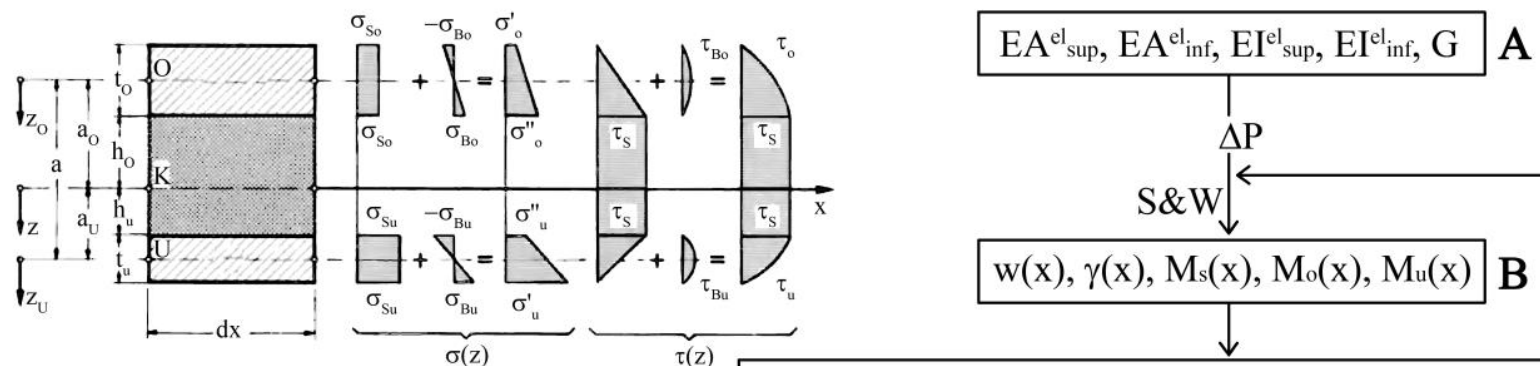

(a)

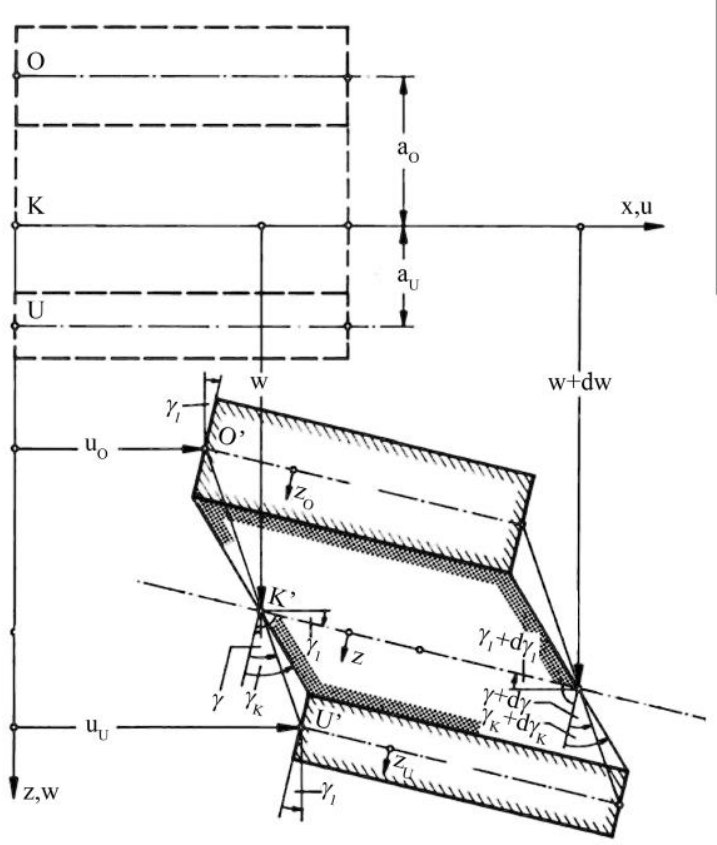

(b)

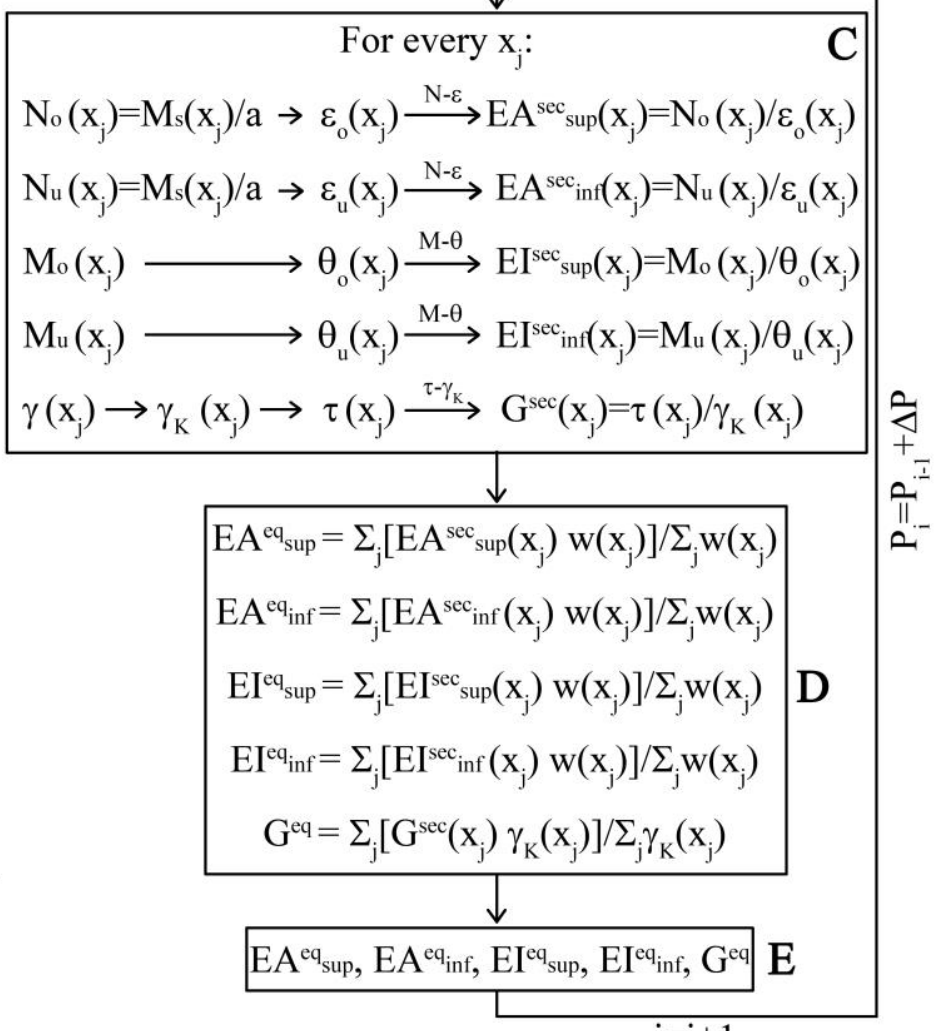

(c)

Fig. 4 Stress distribution (a) and deformed configuration (b) adopted [15]; flow chart of the analytical model (c). 
Table 1 Symbols included in Figure 4

\begin{tabular}{|c|c|}
\hline $\mathrm{a}$ & distance between the centroidal axis of the upper and lower TRC layer \\
\hline$a_{0}$ & distance between the centroidal axis of the beam and the centroidal axis of the upper TRC layer \\
\hline $\mathrm{a}_{\mathrm{u}}$ & distance between the centroidal axis of the beam and the centroidal axis of the lower TRC layer \\
\hline $\mathrm{b}$ & width of the beam \\
\hline $\mathrm{EA}^{\mathrm{el}}{ }_{\mathrm{inf}}$ & initial elastic axial stiffness of lower TRC layer \\
\hline $\mathrm{EA}^{\mathrm{el}}{ }_{\text {sup }}$ & initial elastic axial stiffness of upper TRC layer \\
\hline $\mathrm{EA}^{\mathrm{eq}_{\mathrm{inf}}}$ & equivalent axial stiffness of lower TRC layer \\
\hline $\mathrm{EA}^{\mathrm{eq}}$ sup & equivalent axial stiffness of upper TRC layer \\
\hline $\mathrm{EA}^{\mathrm{sec}_{\text {inf }}}(\mathrm{x})$ & axial stiffness of lower TRC layer defined through a secant approach at coordinate $\mathrm{x}$ \\
\hline $\mathrm{EA}^{\mathrm{sec}} \sup (\mathrm{x})$ & axial stiffness of upper TRC layer defined through a secant approach at coordinate $\mathrm{x}$ \\
\hline $\mathrm{EI}^{\mathrm{el}}{ }_{\mathrm{inf}}$ & initial elastic bending stiffness of lower TRC layer \\
\hline $\mathrm{EI}^{\mathrm{el}}{ }_{\text {sup }}$ & initial elastic bending stiffness of upper TRC layer \\
\hline $\mathrm{EI}^{\mathrm{eq}} \mathrm{inf}_{\mathrm{i}}$ & equivalent bending stiffness of lower TRC layer \\
\hline $\mathrm{EI}^{\mathrm{eq}}$ sup & equivalent bending stiffness of upper TRC layer \\
\hline $\mathrm{EI}^{\mathrm{sec}_{\text {inf }}}(\mathrm{x})$ & bending stiffness of lower TRC layer defined through a secant approach at coordinate $\mathrm{x}$ \\
\hline $\mathrm{EI}^{\mathrm{sec}}{ }_{\text {sup }}(\mathrm{x})$ & bending stiffness of upper TRC layer defined through a secant approach at coordinate $\mathrm{x}$ \\
\hline G & initial shear modulus of the core material \\
\hline $\mathrm{G}^{\mathrm{eq}}$ & equivalent shear modulus of the core material \\
\hline $\mathrm{G}^{\mathrm{sec}}(\mathrm{x})$ & shear modulus of the core defined through a secant approach at coordinate $\mathrm{x}$ \\
\hline $\mathrm{h}$ & thickness of the core \\
\hline$h_{0}$ & thickness of the part of the core above the centroidal axis \\
\hline$h_{u}$ & thickness of the part of the core below the centroidal axis \\
\hline i & $i$-th step \\
\hline $\mathrm{K}$ & point on the centroidal axis of the core \\
\hline $\mathrm{K}^{\prime}$ & point on the centroidal axis of the core in the deformed configuration \\
\hline M- $\theta$ & bending moment vs. curvature relationship \\
\hline $\mathrm{M}_{\mathrm{o}}(\mathrm{x})$ & bending moment of the upper TRC layer at coordinate x $M_{o}=\int_{-t_{o} / 2}^{t_{o} / 2} \sigma_{B o}\left(z_{o}\right) b z d z_{o}$ \\
\hline $\mathrm{M}_{\mathrm{s}}(\mathrm{x})$ & $\begin{array}{l}\text { bending moment due to the sandwich action at coordinate } \mathrm{x} \\
M_{S}=\int_{-t_{o} / 2}^{t_{o} / 2} \sigma_{S o}\left(z_{o}\right) b z d z_{o}+\int_{-t_{u} / 2}^{t_{u} / 2} \sigma_{S u}\left(z_{u}\right) b z d z_{u}\end{array}$ \\
\hline $\mathrm{M}_{\mathrm{u}}(\mathrm{x})$ & bending moment of the lower TRC layer at coordinate x $M_{u}=\int_{-t_{u} / 2}^{t_{u} / 2} \sigma_{B u}\left(z_{u}\right) b z d z_{u}$ \\
\hline $\mathrm{N}-\varepsilon$ & axial force vs. strain relationship \\
\hline $\mathrm{N}_{\mathrm{o}}(\mathrm{x})$ & $\begin{array}{l}\text { axial force in the upper TRC layer due to sandwich action at coordinate x: } \\
N_{o}=\int_{-t_{o} / 2}^{t_{o} / 2} \sigma_{S o}\left(z_{o}\right) b d z_{o}\end{array}$ \\
\hline $\mathrm{N}_{\mathrm{u}}(\mathrm{x})$ & $\begin{array}{l}\text { axial force in the lower TRC layer due to sandwich action at coordinate x: } \\
N_{u}=\int_{-t_{u} / 2}^{t_{u} / 2} \sigma_{S u}\left(z_{u}\right) b d z_{u}\end{array}$ \\
\hline $\mathrm{O}$ & point on the centroidal axis of the upper TRC layer \\
\hline $\mathrm{O}^{\prime}$ & point on the centroidal axis of the upper TRC layer in the deformed configuration \\
\hline $\mathrm{P}_{\mathrm{i}}$ & applied load at $i$-th step \\
\hline$P_{i-1}$ & applied load at $i+1$ step \\
\hline $\mathrm{S} \& \mathrm{~W}$ & application of the Stamm and Witte model \\
\hline$t_{0}$ & thickness of the upper TRC layer \\
\hline$t_{u}$ & thickness of the lower TRC layer \\
\hline $\mathrm{U}$ & point on the centroidal axis of the lower TRC layer \\
\hline U' & point on the centroidal axis of the lower TRC layer in the deformed configuration \\
\hline $\mathrm{u}$ & displacement along the $\mathrm{x}$-axis \\
\hline $\mathrm{u}_{\mathrm{o}}$ & displacement of point $\mathrm{O}$ along the $\mathrm{x}$-axis \\
\hline $\mathrm{u}_{\mathrm{u}}$ & displacement of point $U$ along the $x$-axis \\
\hline $\mathrm{w}$ & displacement of point $\mathrm{K}$ along the $\mathrm{z}$-axis \\
\hline $\mathrm{w}(\mathrm{x})$ & vertical displacement at coordinate $\mathrm{x}$ \\
\hline $\mathrm{x}$ & coordinate along the horizontal axis \\
\hline $\mathrm{x}_{\mathrm{j}}$ & coordinate of the central point of the $j$-th element in which the beam is discretised \\
\hline $\mathrm{z}$ & coordinate along the axis which is orthogonal to the centroidal axis of the beam \\
\hline $\mathrm{z}_{\mathrm{O}}$ & coordinate along the axis perpendicular to the centroidal axis of the upper TRC layer \\
\hline $\begin{array}{l}\mathrm{Z}_{\mathrm{u}} \\
\gamma(\mathrm{x})\end{array}$ & $\begin{array}{l}\text { coordinate along the axis perpendicular to the centroidal axis of the lower TRC layer } \\
\text { global rotation at coordinate } \mathrm{x}\end{array}$ \\
\hline$\gamma_{\mathrm{K}}(\mathrm{x})$ & shear strain of the core at coordinate $\mathrm{x} \quad \gamma_{K}=\frac{a}{h} \gamma$ \\
\hline
\end{tabular}


$\gamma_{1}(\mathrm{x}) \quad$ rotation of the upper and lower TRC layers at coordinate $\mathrm{x}$

$\Delta \mathrm{P} \quad$ increment of load

$\varepsilon_{0}(\mathrm{x}) \quad$ axial strain of the upper TRC layer at coordinate $\mathrm{x}$

$\varepsilon_{\mathrm{u}}(\mathrm{x}) \quad$ axial strain of the lower TRC layer at coordinate $\mathrm{x}$

$\theta_{\mathrm{o}}(\mathrm{x}) \quad$ curvature of the upper TRC layer at coordinate $\mathrm{x}$

$\theta_{\mathrm{u}}(\mathrm{x}) \quad$ curvature of the lower TRC layer at coordinate $\mathrm{x}$

$\sigma(\mathrm{z}) \quad$ normal stress of the sandwich beam at generalised position $\mathrm{z}$

$\sigma_{\mathrm{Bo}} \quad$ maximum normal stress of the upper TRC layer due to $\mathrm{M}_{\mathrm{o}}$

$\sigma_{\mathrm{Bo}}\left(\mathrm{z}_{\mathrm{o}}\right) \quad$ maximum normal stress of the upper TRC layer due to $\mathrm{M}_{\mathrm{o}}$ at position $\mathrm{z}_{\mathrm{o}}$

$\sigma_{\mathrm{Bu}} \quad$ maximum normal stress of the lower TRC layer due to $\mathrm{M}_{\mathrm{u}}$

$\sigma_{\mathrm{Bu}}\left(\mathrm{z}_{\mathrm{u}}\right) \quad$ maximum normal stress of the lower TRC layer due to $\mathrm{M}_{\mathrm{u}}$ at position $\mathrm{z}_{\mathrm{u}}$

$\sigma_{\mathrm{o}}^{\prime}, \sigma^{\prime \prime} \quad$ minimum and maximum normal stress of the upper TRC layer due to both $\mathrm{M}_{\mathrm{o}}$ and $\mathrm{M}_{\mathrm{S}}$

$\sigma_{\mathrm{u}}^{\prime}, \sigma_{\mathrm{u}}^{\prime \prime} \quad$ maximum and minimum normal stress of the lower TRC layer due to both $\mathrm{M}_{\mathrm{u}}$ and $\mathrm{M}_{\mathrm{S}}$

$\sigma_{S o} \quad$ normal stress of the upper TRC layer due to $\mathrm{M}_{\mathrm{S}}$

$\sigma_{\mathrm{So}}\left(\mathrm{z}_{\mathrm{o}}\right) \quad$ normal stress of the upper TRC layer due to $\mathrm{M}_{\mathrm{S}}$ at position $\mathrm{z}_{\mathrm{O}}$

$\sigma_{\mathrm{Su}} \quad$ normal stress of the lower TRC layer due to $\mathrm{M}_{\mathrm{S}}$

$\sigma_{\mathrm{Su}}\left(\mathrm{z}_{\mathrm{u}}\right) \quad$ normal stress of the lower TRC layer due to $\mathrm{M}_{\mathrm{S}}$ at position $\mathrm{z}_{\mathrm{u}}$

$\tau-\gamma_{\mathrm{K}} \quad$ shear stress vs. shear strain relationship of the core

$\tau(\mathrm{x}) \quad$ shear stress of the core at coordinate $\mathrm{x}$

$\tau(\mathrm{z}) \quad$ shear stress of the beam at generalised position $\mathrm{z}$

$\tau_{\mathrm{Bo}} \quad$ maximum shear stress of the upper TRC layer due to the bending of the layer itself

$\tau_{\mathrm{Bu}} \quad$ maximum shear stress of the lower TRC layer due to the bending of the layer itself

$\tau_{\mathrm{o}} \quad$ shear stresses in the upper TRC layer at position $\mathrm{z}_{\mathrm{o}}$

$\tau_{\mathrm{S}} \quad$ shear stresses of the core

$\tau_{\mathrm{u}}$

shear stresses in the lower TRC layer at position $\mathrm{z}_{\mathrm{u}}$

At the beginning, the initial elastic stiffness values of both TRC layers $\left(\mathrm{EA}^{\mathrm{el}}{ }_{\text {sup }}, \mathrm{EA}^{\mathrm{el}}{ }_{\text {inf }}, \mathrm{EI}^{\mathrm{el}}{ }_{\text {sup }}\right.$ and $\left.\mathrm{EI}^{\mathrm{el}}{ }_{\text {inf }}\right)$ and the core initial shear modulus $\mathrm{G}$ are imposed (step $\mathbf{A}$ - Figure 4(c)). The load, initially null, is incremented by $\Delta \mathrm{P}$ and the values of the vertical displacement $\mathrm{w}$, the rotation $\gamma$, the bending moments $\mathbf{M}_{\mathrm{s}}, \mathbf{M}_{\mathrm{o}}$ and $\mathbf{M}_{\mathrm{u}}$ are computed according to the Stamm and Witte classical model as a function of the coordinate $\mathrm{x}$ along the beam length (step $\mathbf{B}$ - Figure 4(c)).

Once the material behaviour becomes non-linear, membrane and bending stiffness values of each element are computed by means of a secant approach referring to generalised constitutive laws (M- $\theta$, with $\theta=$ curvature, and $\mathrm{N}-\varepsilon)$ for the TRC layers and to a shear $\left(\tau-\gamma_{\mathrm{K}}\right)$ constitutive relationship for the EPS (step C - Figure 4(c)). A proper description of these constitutive relationships is provided in Section 3.1. Referring to a generic $i$-th step, for TRC layers, the stiffness values at position $\mathrm{x}$ are defined starting from $\mathrm{M}$ and $\mathrm{N}$ evaluated at the previous $(i-1)$ step for that position. Generalised constitutive laws allow to define the corresponding $\theta$ and $\varepsilon$ respectively and, therefore, axial $\left(\mathrm{EA}^{\mathrm{sec}}=\mathrm{N} / \varepsilon\right)$ and bending $\left(\mathrm{EI}^{\mathrm{sec}}=\mathrm{M} / \theta\right)$ stiffness. A similar approach is adopted for EPS: $\gamma$, and hence $\gamma_{\mathrm{K}}$, are computed from the model at step $(i-$ 1); the $\left(\tau-\gamma_{\mathrm{K}}\right)$ constitutive law allows to define the corresponding value of $\tau$ and, therefore, secant shear modulus at $i$-th step is defined as $\mathrm{G}^{\mathrm{sec}}=\tau / \gamma_{\mathrm{K}}$. It is worth noting that, in the model, axial and bending actions acting on the external faces are uncoupled.

Stamm and Witte differential equations ask for unique stiffness for each layer; in order to define equivalent stiffness to be used, the local stiffness values evaluated for each element are weighted according to different response parameters 
evaluated by using the displacement $\mathrm{w}$ as weighting function, while equivalent shear modulus $\left(\mathrm{G}^{\mathrm{eq}}\right)$ of EPS considers shear deformation as a weighting function.

It is worth to underline that a strong assumption of the Stamm and Witte model is to consider the same rotation for the upper and the lower TRC layers (see Figure 4(b)).

Moreover, in the implemented model, global stiffness values of each layer derive from an average process, along the beam axis, of local stiffness values defined according to constitutive models. This process leads to global stiffness values that do not directly respect the generalised constitutive laws at each point.

\subsection{Generalised constitutive relationships}

The constitutive relationships introduced in the analytical model are described in this section.

The axial and the bending behaviour of TRC are described by means of generalised constitutive models and, as already discussed, no interaction is considered between them. As discussed in the following (Section 3.2, Figure 7), this assumption does not lead to any influence in considering the membrane stiffness of the TRC layers, but may cause a difference in the computation of the bending stiffness of these layers, especially in the bottom one that is subjected to tension. Nevertheless, it can be demonstrated that this difference has a negligible effect $(<5 \%)$ on the global response of the sandwich.

Regarding the axial behaviour, axial force $(\mathrm{N})$ vs. axial strain $(\varepsilon)$ relationship is considered.

In compression, an elastic behaviour is assumed for TRC, considering an elastic modulus of 30 GPa (according to literature results on cement matrix characterised by similar compressive strength and maximum aggregate size [31]).

In tension, the stress-strain behaviour shown in Figure 2(a) is assumed for TRC (see "TRC_const. law" curve).

The bending behaviour of the TRC external layers is described by M- $\theta$ diagrams built considering the plane section kinematic assumption [32].

In Figure 5 the $\mathrm{M}-\theta$ relationships assigned to the bending behaviour of external layers are shown. Two relationships representing extreme situations are proposed: a lower bound situation in which the fabric contribution in bending is neglected ("plain concrete", this represents the situation in which fabric is always on the neutral axis), and a situation in which the contribution of the fabric is accounted and spread all over the thickness of the layer ("TRC"). In both cases, the compressive behaviour is described through a parabolic-rectangular stress-strain relationship [33] considering a maximum strength $\mathrm{f}_{\mathrm{cm}}$ equal to $71.86 \mathrm{MPa}$ (average cubic compressive strength experimentally measured); this strength is reached at a strain equal to 0.002 , while the failure takes place at a strain equal to 0.0035 . In tension, when neglecting the fabric contribution, the formulation proposed by MC2010 [33] for plain concrete is adopted, considering an average tensile strength of 4.1 MPa (C50 class of concrete) and the same elastic modulus of $30 \mathrm{GPa}$ assumed above. When the fabric 

build the M- $\theta$ diagram.

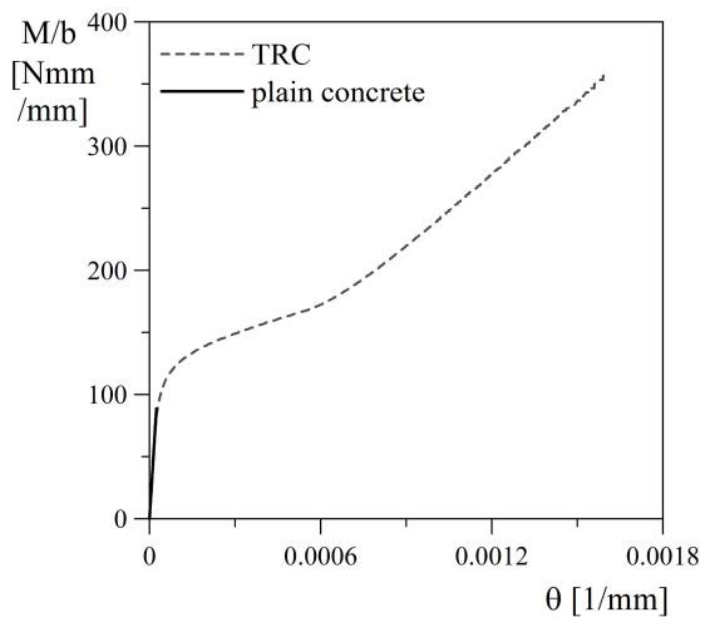

Fig. 5 M- $\theta$ constitutive relationships used in the analytical model.

The EPS $\left(\tau-\gamma_{\mathrm{K}}\right)$ relationship adopted in the model is assumed to be elasto-perfectly plastic. The values of shear modulus $\mathrm{G}$ and maximum shear stress $\bar{\tau}$ are identified from the experimental tests presented in Section 2.3 ; the average values equal to 5.04 and $0.16 \mathrm{MPa}$ are used respectively for $\mathrm{G}$ and $\bar{\tau}$. These values are close to those found in literature: considering the empirical correlations deduced by Gnip et al. [34], that relate the density of EPS with shear modulus and ultimate strength, a shear modulus equal to $4.64 \mathrm{MPa}$ and a maximum shear stress equal to $0.144 \mathrm{MPa}$ could be expected.

\subsection{Analytical results}

The results of the analytical model are shown in Figure 6 in terms of load (P) versus displacement $(\delta)$ curves for both the deep and slender sandwich beams. For each beam size, two curves are proposed, depending on the M- $\theta$ relationship used in the model (plain concrete "PC" or textile reinforced concrete "TRC"). In the figure, the analytical responses are compared with the experimental results already presented and discussed in [26].

The small membrane compressive stress achieved in the upper TRC layer $\left(\sigma_{\mathrm{c}}<8 \mathrm{MPa}\right)$ justifies the linear elastic assumption for this behaviour.

In the case of deep sandwich beams, both the predictions overestimate the specimen behaviour. For slender sandwich beams, the analytical predictions are practically overlapped to the experimental curves.

Even if the contribution of the fabric on the bending behaviour of TRC faces is relevant, as it can be observed in the M$\theta$ diagram (see Figure 5), the difference between the global response either neglecting or considering TRC bending contribution is limited. This result confirms the experimental evidence [26] according to which the fabric position within the external layers has a low influence on the global sandwich response, only affecting the crack pattern of the specimen. In fact, the fabric location can affect the M- $\theta$ curve reducing the post-peak significantly when placed at the TRC layer 

still un-cracked regions.

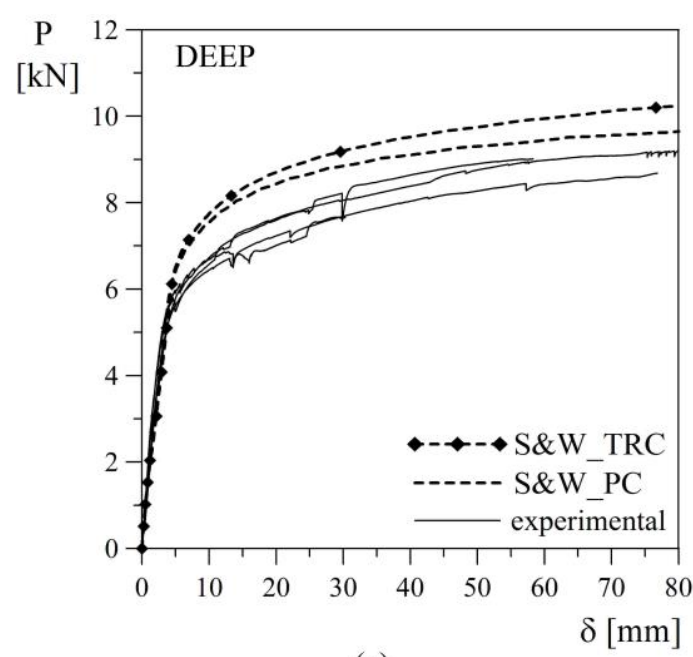

(a)

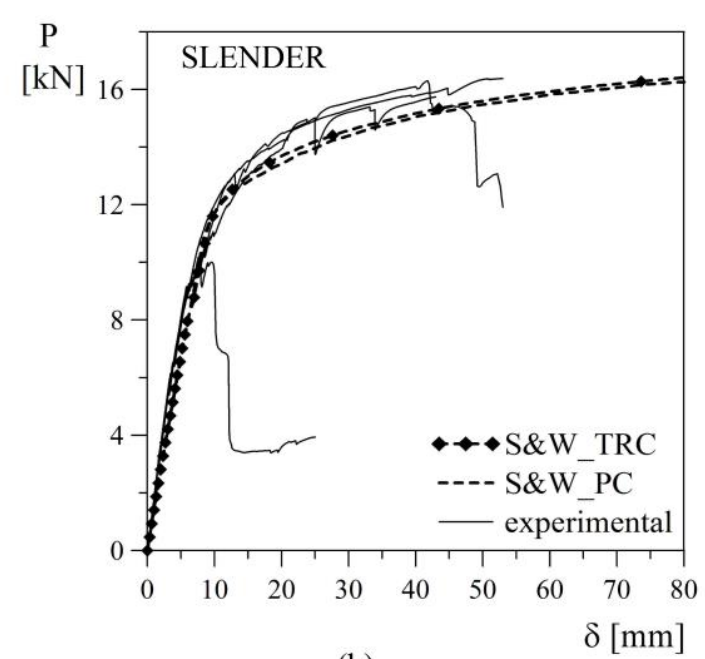

(b)

Fig. 6 Analytical prediction for deep (a) and slender (b) sandwich beam compared with the experimental results [26].

In Figure 7, the effect of the M-N interaction is discussed (slender sandwich beams are taken into account). Figure 7(a) compares the relationships between moment and curvature whether or not considering the interaction between $\mathrm{M}$ and $\mathrm{N}$. In particular, the $\theta-\mathrm{M}$ diagram adopted in the model that neglects this interaction is compared with some points that have bending stiffness of about $34 \%$. been obtained considering a coupled approach. In the definition of these points, for a given value of $\mathrm{M}$ and $\mathrm{N}$, both rotational and translational equilibrium were imposed in order to define the corresponding curvature $\theta$. These $\mathrm{M}-\mathrm{N}$ points were directly selected from the results of "S\&W_TRC" model previously presented. This comparison shows that the uncoupled approach, which adopts the secant approach, underestimates the curvature thus causing an overestimation of the The effect of a reduced bending stiffness is shown in Figure $7 \mathrm{~b}$, in which the sandwich responses corresponding to different bending stiffness reductions are considered. In particular, the situation with $0 \%$ EI corresponds to the Plantema solution in which the external layers just provide a membrane contribution. The case of $66 \%$ EI represents the bending stiffness reduction due to $\mathrm{M}-\mathrm{N}$ interaction previously discussed. It is worth noting that this curve just considers a uniform stiffness reduction along the beam without taking into account the real membrane stress variation; therefore, it represents a lower bound of the sandwich response. For this reason and because of the small difference between the $100 \%$ EI and $66 \%$ EI responses, the M-N un-coupled approach can be considered as reliable.

It is worth noting that the model is not able to predict the specimen failure as no failure criterion is introduced. 


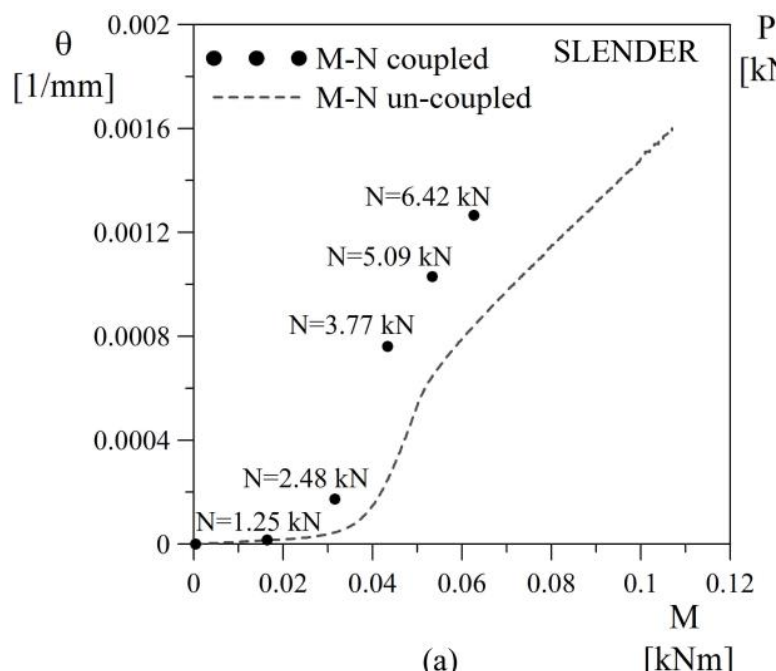

(a)

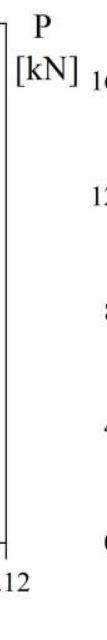

$[\mathrm{kNm}]$

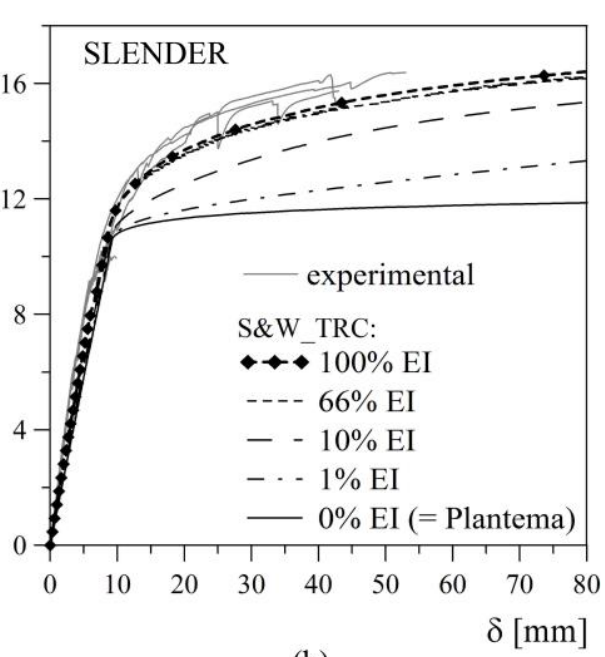

(b)

Fig. 7 Influence of M-N interaction for slender sandwich beam: effect on curvature (a) and effect of TRC stiffness on

\section{FE model for sandwich beams}

A prediction of the behaviour of the sandwich beams was also performed by means of 3D numerical FE models, developed with the finite element program ABAQUS/Standard 6.12.

The constitutive laws used in the Abaqus finite element models for textile reinforced concrete and expanded polystyrene are presented and discussed in Sections 4.1 and 4.2. Then, the reliability of these adopted relationships is validated in Section 4.3, with reference to experimental tests performed on TRC and EPS specimens, whose results have been already shown in Sections 2.2 and 2.3 respectively. The sandwich beam model description is provided in Section 4.4 and the finite element analysis results are provided and discussed in Section 4.5.

\subsection{TRC layer behaviour}

The elastic phase is defined through two parameters: the Young's modulus, assumed equal to 30 GPa according to literature results on cement matrix characterised by similar compressive strength and maximum aggregate size [31]; the Poisson's ratio, assumed equal to 0.2 .

Plasticity is accounted by Concrete Damage Plasticity model [35], which is implemented in Abaqus. The model is a continuum plasticity-based model for concrete. It assumes that the main two failure mechanisms are tensile cracking and compressive crushing of the concrete material. The evolution of the yield (or failure) surface is controlled by two hardening variables, $\tilde{\varepsilon}_{t}^{p l}$ (tensile equivalent plastic strain) and $\tilde{\varepsilon}_{c}^{p l}$ (compressive equivalent plastic strain), linked to failure mechanisms under tension and compression loading, respectively [36, 37]. as a plasticity model. 
The compressive behaviour is assumed to be elasto-perfectly plastic, with a yield stress equal to $72 \mathrm{MPa}$ according to experimental results presented in Section 2.2.

The plastic tensile behaviour is defined by a stress-strain relationship, already discussed in Section 2.2 (see Figure 2(a), "TRC_const. law"). Some relevant points typical of the TRC tensile behaviour are highlighted in the figure on the constitutive law curve: T1 corresponds to the beginning of the multi-cracking branch; T2 represents the point after which only the contribution of fabric and tension stiffening are acting; and T3 corresponds to the brittle failure of the fabric. In the Concrete Damage Plasticity model the tensile behaviour of TRC layers is assumed homogeneous over the layer thickness. The reliability of this assumption is discussed in Section 4.3.1.

\subsection{EPS layer behaviour}

The elastic phase of EPS is defined by introducing a Young's modulus equal to 13.7 MPa (Section 2.3) and a Poisson's ratio equal to 0.1 .

To account for plasticity, Crushable Foam model with volumetric hardening implemented in ABAQUS is used [36]. The phenomenological isotropic model was originally developed, for metallic foams, by Deshpande and Flek [38]. The model assumes that the evolution of the yield surface is controlled by the volumetric compacting plastic strain experienced by the material.

This model has also a pressure-dependent yield surface with an elliptical shape in the meridional $(p-q)$ stress plane (with $p=$ hydrostatic stress and $q=$ Von Mises stress) and a Von Mises circle in the deviatoric stress plane. uniaxial $\left(\sigma_{c}^{0}\right)$ and the hydrostatic $\left(p_{c}^{0}\right)$ compressive strength and the ratio $k_{t}$ between the hydrostatic tensile $\left(p_{t}\right)$ and the hydrostatic compressive $\left(p_{c}^{0}\right)$ strength.

The compression yield stress ratio $k$ can vary between 0 and 3 , and the hydrostatic yield stress ratio $k_{t}$ has to be equal or higher than 0 .

The evolution of the yield surface follows the volumetric hardening rule, which is controlled by the volumetric plastic strain $\left(-\varepsilon_{v o l}^{p l}\right)$ experienced by the material. The hardening law is introduced in the model by using the uniaxial compression test data (uniaxial compression yield stress as a function of axial plastic strain), considering the fact that, in uniaxial compression, $\varepsilon_{\text {axial }}^{p l}=\varepsilon_{v o l}^{p l}$.

The model parameters were set in order to impose the initial yielding surface to satisfy the following conditions:

- the uniaxial compressive yield stress $\left(\sigma_{c}^{0}\right)$ is equal to that obtained from the experimental tests in uniaxial compression at the end of the initial linear branch (average value obtained from three tests on nominally identical 
specimens: $\sigma_{c_{-} a v}^{0}=0.188 \mathrm{MPa}$ ). This condition means that the initial yield surface passes through the point $\left(p=\sigma_{c_{-} a v}^{0} / 3 ; q=\sigma_{c_{-} a v}^{0}\right)$

- the uniaxial tensile yield stress $\left(\sigma_{t}^{0}\right)$ is equal to that obtained from the experimental tests in uniaxial tension at the peak (average value obtained from three tests on nominally identical specimens: $\sigma_{t_{-} a v}^{0}=0.392 M P a$ ). This condition means that the initial yield surface passes through the point $\left(p=-\sigma_{t_{-} a v}^{0} / 3 ; q=\sigma_{t_{-} a v}^{0}\right)$;

- the shear yield stress $(\tilde{\tau})$ is equal to that obtained from the experimental shear tests (average value obtained from three tests on nominally identical specimens: $\tilde{\tau}_{a v}=0.160 \mathrm{MPa}$ ). This condition means that the initial yield surface passes through the point $\left(p=0 ; q=\sqrt{3} \tilde{\tau}_{a v}\right)$.

The resulting ratios $k$ and $k_{t}$ are equal to 1.59 and 54.30 respectively; the corresponding initial yield surface plotted in the $p-q$ stress plane is shown in Figure 8 (solid line). Experimental results performed on EPS are shown in the figure through round markers.

It is worth noting that the material simulated by this model has a hardening behaviour in uniaxial tension, which does not comply with the brittle failure of EPS in tension; hence, it is necessary to verify if the EPS tensile strength is exceeded or not, in order to check if a tensile failure of the core occurs.

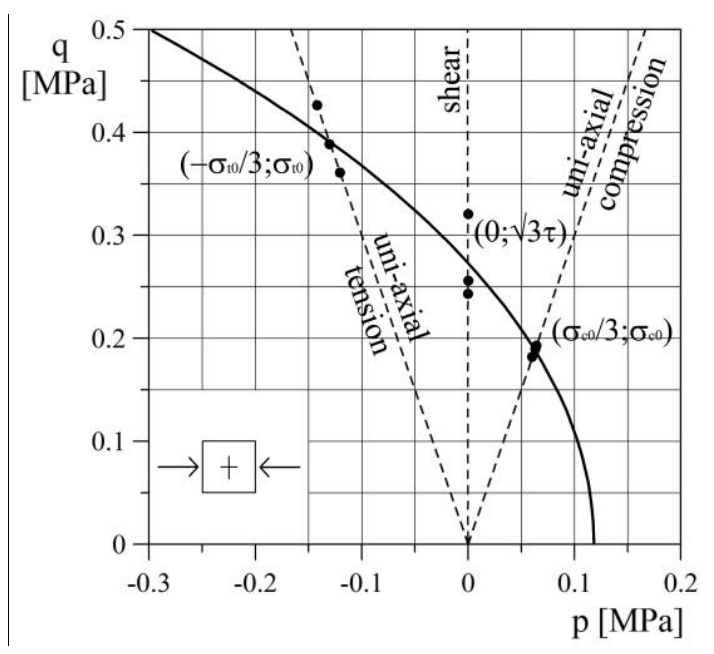

Fig. 8 Crushable Foam model: adopted initial yield surface (solid line) in the $p$ - $q$ plane for $k=1.59$ and $k_{t}=54.30$ : round markers represent experimental results; dashed lines correspond to uniaxial tension, uniaxial compression and shear domain.

\subsection{Reliability assessment of the constitutive models}

This section aims to discuss the reliability of the constitutive models adopted and some crucial assumptions taken into account in the FEM analysis of the sandwich beams presented.

In particular, two main issues are discussed: (a) the use of a homogeneous tensile behaviour of TRC layers over the thickness even if bending moment is acting; (b) the choice of the hardening curve assumed for the EPS model. 


\subsubsection{Modelling of the bending behaviour of TRC layer}

As already discussed, the tensile behaviour of TRC layers is assumed homogeneous over the thickness and, in particular, the uniaxial tensile constitutive law derived from uniaxial tensile tests (Section 2.2) is applied to the whole concrete layer disregarding the real fabric position.

The uniaxial tensile constitutive law is introduced in Abaqus referring to plastic strain. The curve adopted is reported in Figure 2(a) (“TRC_const. law").

In order to assess the reliability of this choice, bending tests performed on TRC specimens (Section 2.2) have been modelled in ABAQUS by considering this assumption.

The specimen is modelled as a solid homogeneous section and it is discretised by means of 8-node linear brick elements (C3D8R). The characteristics of the finite element mesh related to TRC are collected in the second column of Table 2; in particular, the number of nodes, the number of elements, the number of elements over the thickness and the maximum aspect ratio (ratio between the longest and shortest edge of an element) are specified.

The load-displacement curve resulting from the simulation is superimposed to the experimental results in Figure 2(b). Looking at the figure it is possible to observe that the numerical response is in good agreement with the experimental behaviour of TRC in bending. This result shows that considering TRC as a homogeneous material over a thickness of 10 mm allows to adequately predict the bending behaviour of TRC.

Table 2 Mesh characteristics of FE models

\begin{tabular}{|c|c|c|c|c|c|c|}
\hline Model & $\begin{array}{c}\text { TRC } \\
\text { (bending) }\end{array}$ & $\begin{array}{c}\text { EPS } \\
\text { (compression) } \\
\end{array}$ & \multicolumn{2}{|c|}{ Deep sandwich beam } & \multicolumn{2}{|c|}{ Slender sandwich beam } \\
\hline \multirow{3}{*}{ Nodes } & \multirow{3}{*}{4692} & \multirow{3}{*}{58956} & $\mathrm{TRC}_{\text {sup }}$ & 10400 & $\mathrm{TRC}_{\text {sup }}$ & 15128 \\
\hline & & & EPS & 28600 & EPS & 41602 \\
\hline & & & $\mathrm{TRC}_{\text {inf }}$ & 10400 & $\mathrm{TRC}_{\mathrm{inf}}$ & 15128 \\
\hline \multirow{3}{*}{ Elements } & \multirow{3}{*}{3264} & \multirow{3}{*}{54450} & $\mathrm{TRC}_{\text {sup }}$ & 7425 & $\mathrm{TRC}_{\text {sup }}$ & 10890 \\
\hline & & & EPS & 24750 & EPS & 36300 \\
\hline & & & $\mathrm{TRC}_{\text {inf }}$ & 7425 & $\mathrm{TRC}_{\mathrm{inf}}$ & 10890 \\
\hline \multirow{3}{*}{$\begin{array}{l}\text { Elements over } \\
\text { the thickness }\end{array}$} & \multirow{3}{*}{3} & \multirow{3}{*}{50} & $\mathrm{TRC}_{\text {sup }}$ & 3 & $\mathrm{TRC}_{\text {sup }}$ & 3 \\
\hline & & & EPS & 10 & EPS & 10 \\
\hline & & & $\mathrm{TRC}_{\mathrm{inf}}$ & 3 & $\mathrm{TRC}_{\mathrm{inf}}$ & 3 \\
\hline \multirow{3}{*}{$\begin{array}{l}\text { Max. aspect } \\
\text { ratio }\end{array}$} & \multirow{3}{*}{1.9} & \multirow{3}{*}{1.0} & $\mathrm{TRC}_{\text {sup }}$ & 1.9 & $\mathrm{TRC}_{\text {sup }}$ & 3.1 \\
\hline & & & EPS & 1.9 & EPS & 1.1 \\
\hline & & & $\mathrm{TRC}_{\mathrm{inf}}$ & 2.3 & $\mathrm{TRC}_{\mathrm{inf}}$ & 3.1 \\
\hline
\end{tabular}

It is worth mentioning that no failure criterion is introduced in the model, therefore Abaqus code maintains the last stress level of the constitutive curve when the maximum strain of the constitutive law is exceeded.

Furthermore, the change of slope observable in the numerical curve at a load of about $0.5 \mathrm{kN}$ corresponds to the situation in which the maximum strain of the constitutive law (Figure 2(a), $\left.\varepsilon_{\max }=1.37 \mathrm{e}-2\right)$ is reached at the intrados of the specimen. After this point the numerical curve is represented by a dotted line. 
The numerical curve is stopped when the maximum strain of the constitutive law (Figure $\left.2(\mathrm{a}), \varepsilon_{\max }=1.37 \mathrm{e}-2\right)$ is reached at the mid-height of the cross-section, where the fabric is supposed to be placed.

\subsubsection{Modelling of the compressive behaviour of EPS}

In order to assess the reliability of the parameters adopted for EPS and to validate the hardening law introduced, a numerical model of the uniaxial compressive tests made on EPS prisms described in Section 2.3 was performed. A solid homogeneous section discretised through 8-node linear brick elements (C3D8R) with a dimension $3.03 \times 3.03 \times 3 \mathrm{~mm}^{3}$ was used; the mesh characteristics are collected in the third column of Table 2. In Figure 3(a) the numerical curve in terms of nominal stress vs. nominal strain (variables defined as in the experimental test results) is compared with experimental data and a good agreement is achieved. In the same figure point E1 is highlighted: once this point is reached, a significant change in the slope of the response is registered.

\subsection{Sandwich beam model description}

Both deep and slender sandwich beams described in Section 2.1, having the size $550 \times 150 \times 120 \mathrm{~mm}^{3}$ and $1200 \times 300 \times 120 \mathrm{~mm}^{3}$ respectively, are modelled in ABAQUS.

The TRC layers, the EPS layer and the steel plates are all modelled as homogeneous solid, assuming perfect bond at interfaces. The perfect bond assumed at the TRC/EPS interface, with no interface elements introduced, constitutes a strong assumption of the model, but, as no detachment was observed during experimental tests, this assumption is expected to be reliable. TRC layers, EPS layer and steel plates are discretised with 8-node linear brick elements (C3D8R). The characteristics of the finite element mesh are reported in Table 2 for both the models; in particular, the number of nodes, the number of elements, the number of elements over the thickness and the maximum aspect ratio are specified.

TRC and EPS layer behaviour is defined in the finite element software as specified in Sections 4.1 and 4.2, while steel plates used to reduce stress concentration in sandwich beam tests are assumed to be elastic, with a Young's modulus equal to $210 \mathrm{GPa}$ and a Poisson's ratio equal to 0.3 . The same boundary conditions were adopted for both panel geometries investigated. These boundary conditions are shown in Figure 9(a) taking the deep panel as a reference. The meshes of the models are represented in Figure 9(a) and (b) for the deep and slender panels respectively. 


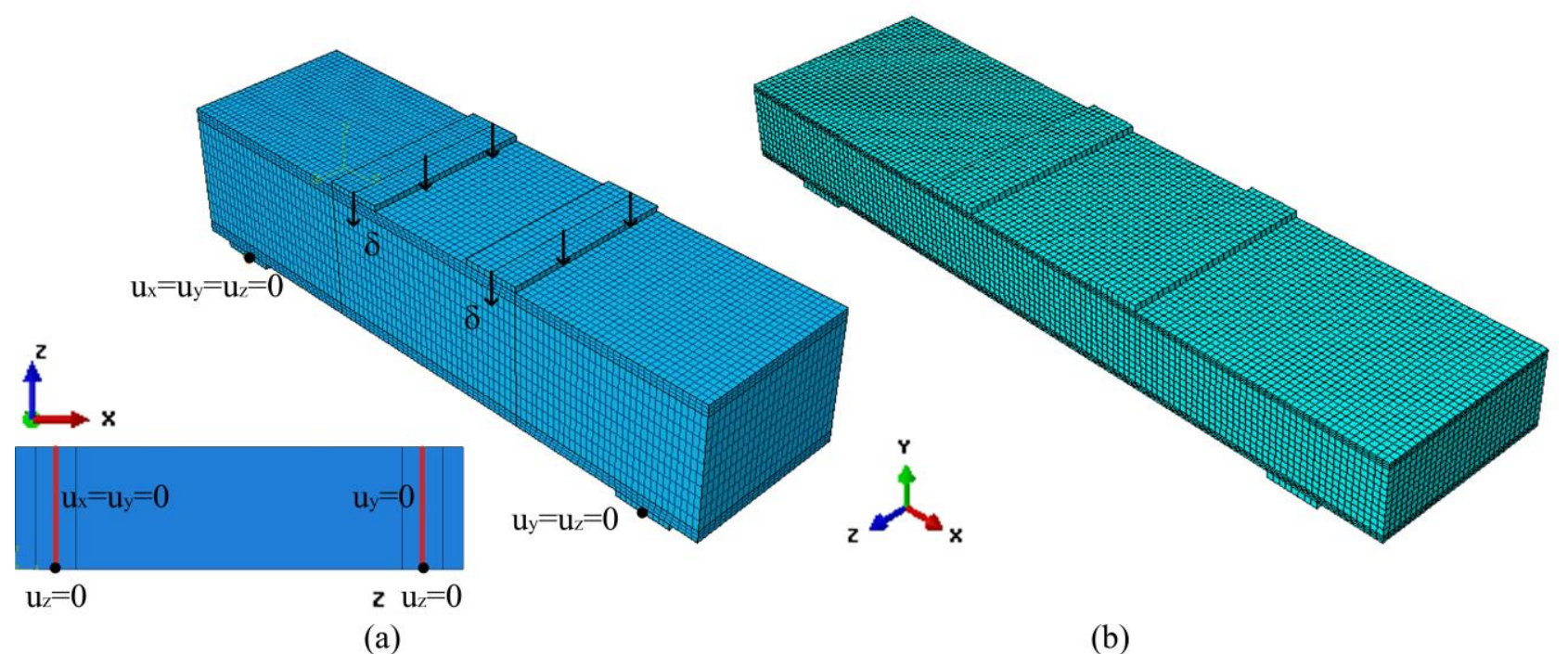

(a)

(b)

Fig. 9 FEM model of sandwich beams: geometry with constraints (a); mesh of deep (a) and slender (b) beam.

\subsection{FEM results}

\subsubsection{Deep sandwich beam}

The numerical result obtained for a deep sandwich beam is shown in Figure 10 in terms of load $(P)$ versus vertical displacement $(\delta)$ curve. This curve is compared to the experimental results already presented in [26]: reliable prediction of the experimental results is achieved.

In the figure, some relevant points are highlighted on the numerical curve. In particular, concerning the TRC tensile constitutive law: point $T 1($ sup $)+T l($ inf $)$ indicates when the upper and the lower TRC layers start to crack only in one point; points $T 2$ (sup) and $T 2($ inf $)$ indicate the end of the multi-cracking phase respectively for the upper and the lower TRC layer at the intrados only in one point; point $T 3($ sup) indicates the reaching of tensile strength at the intrados of the upper TRC layer only in one point.

The numerical analysis confirms the experimental evidence that both TRC layers are cracked, which is indicative that the deep beam was acting as a partially composite sandwich. 


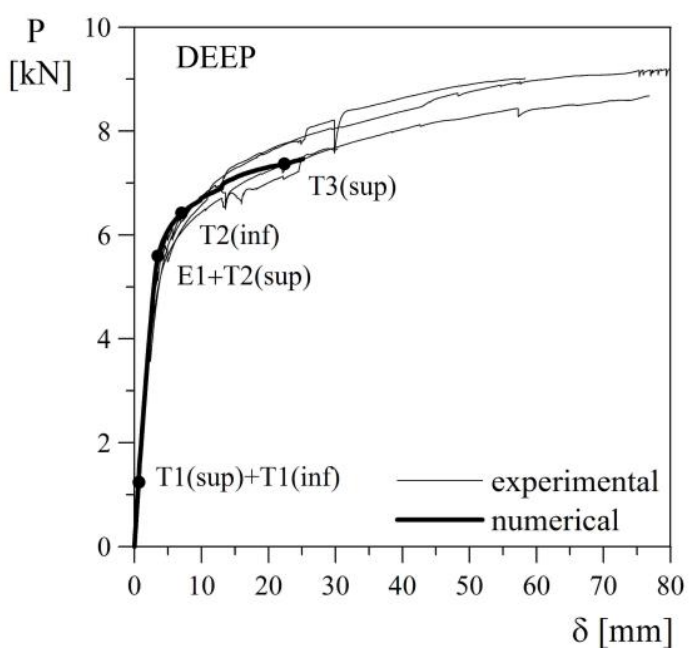

Fig. 10 FEM results - vertical load vs. displacement curves for deep sandwich beam.

It is worth noting that, even if the TRC is cracked, the global response remains almost linear up to point $E 1$, after which

EPS foam starts to yield in compression. In fact, the significant change in the slope of the composite global response is related to the yielding of a compressive strut in the EPS layer when point E1 is reached. This compressive strut is well visible in Figure 11(a), where the minimum principal plastic strains of EPS are shown, and in Figure 11(c) and (d), in which maximum principal plastic strains are plotted.

The numerical analysis stops because of the incompatibility of the deformations of EPS and TRC at the interface caused bond with TRC causing large distortions of the elements thus neglecting convergence of the numerical solution.
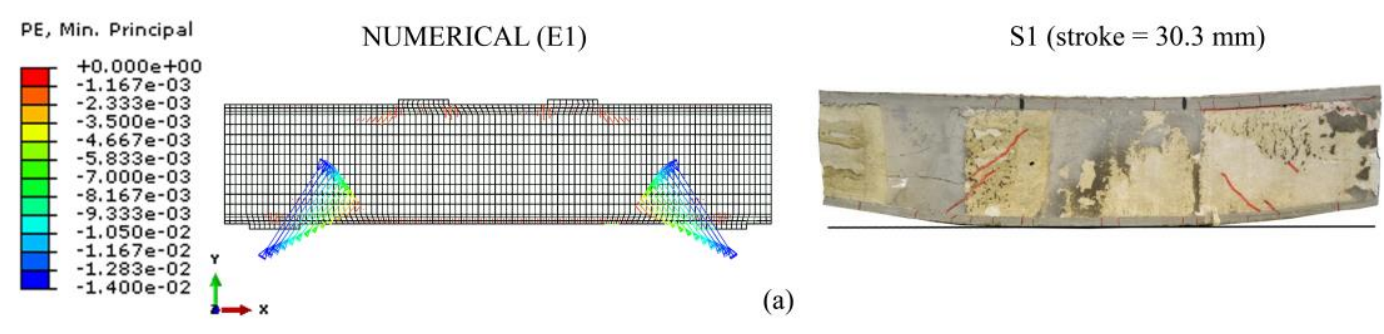

(a)
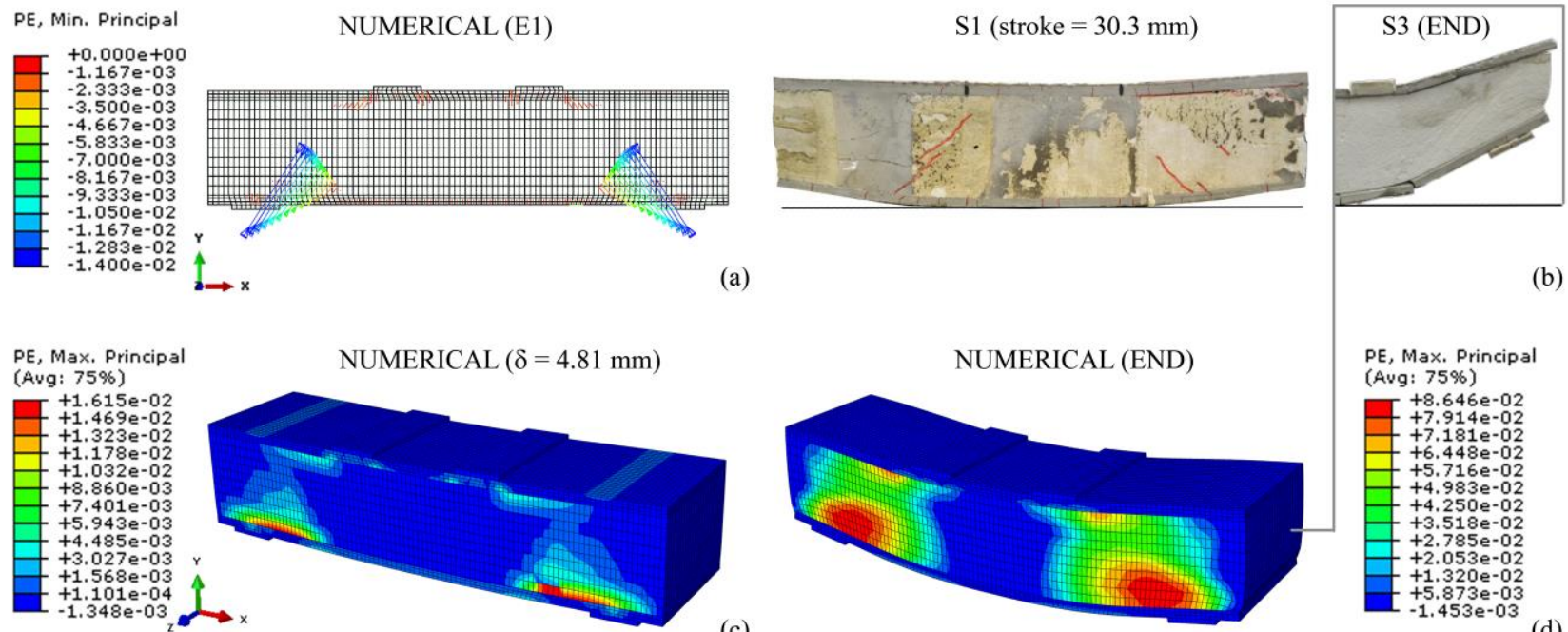

NUMERICAL $(\delta=4.81 \mathrm{~mm})$
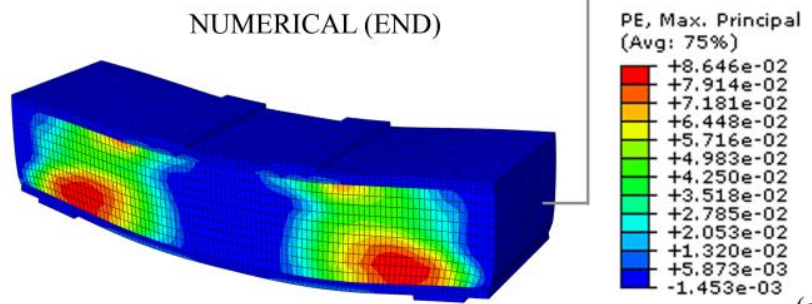

(d)

Fig. 11 FEM model of deep sandwich beam - yielding of a compressive strut in the EPS layer: minimum principal plastic strain at point $E 1$ (a), picture of specimen S1 and S3 after test (b), maximum principal plastic strain at $\delta=4.81 \mathrm{~mm}$ (c) and maximum principal plastic strain at the end of the analysis (d) [COLOR PRINT] 
The multi-cracking phenomenon, observable in both the TRC layers, is shown in Figure 12 by displaying the maximum principal plastic strains of TRC; in the same figure, the crack pattern of specimen S1 is shown (lateral and bottom view). Comparing the pictures related to numerical analysis and experimental test, it is possible to state that the numerical analysis well represents the regions involved in multi-cracking: in the upper TRC layer cracks form under the loading knives, while the lower TRC layer is cracked along the whole length.

It is possible to state that the numerical solution well represents the behaviour of the composite sandwich beam, not only in terms of load versus displacement curve, but also in terms of identification of the involved mechanisms. On the contrary, the ductility is not adequately captured.

Nevertheless, because of the large displacement reached and the good prediction achieved, this approach can be considered a valuable tool for the design of this kind of structures.

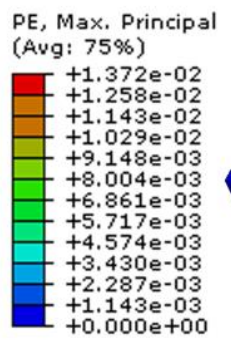

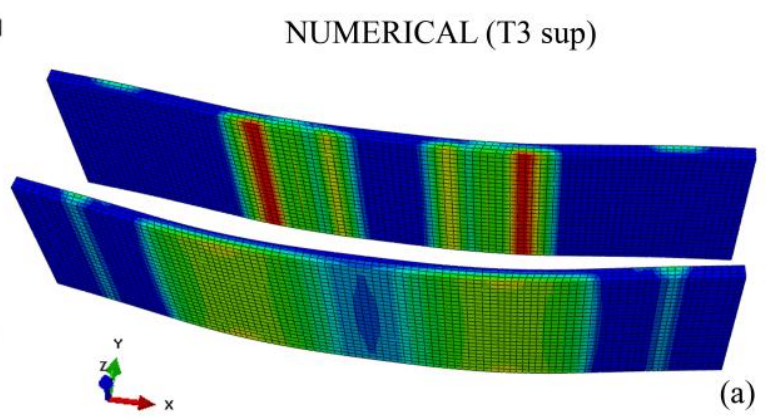

$\mathrm{S} 1($ stroke $=30.3 \mathrm{~mm})$

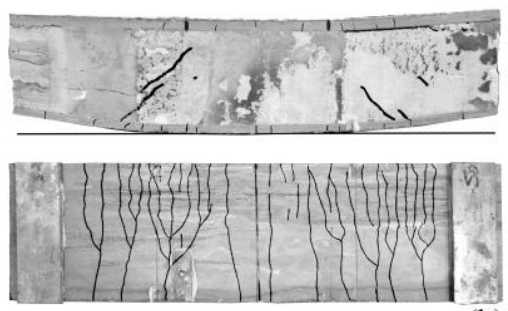

(b)

Fig. 12 FEM model of deep sandwich beam - multi-cracking of both TRC layers: maximum principal plastic strain at point T3sup (a) and pictures of specimen S1 at the end of the test (b): side (top) and intrados (bottom) view. [COLOR

\subsubsection{Slender sandwich beam}

The results of the numerical analysis performed for the slender sandwich beam are shown in Figures 13,14 and 15 .

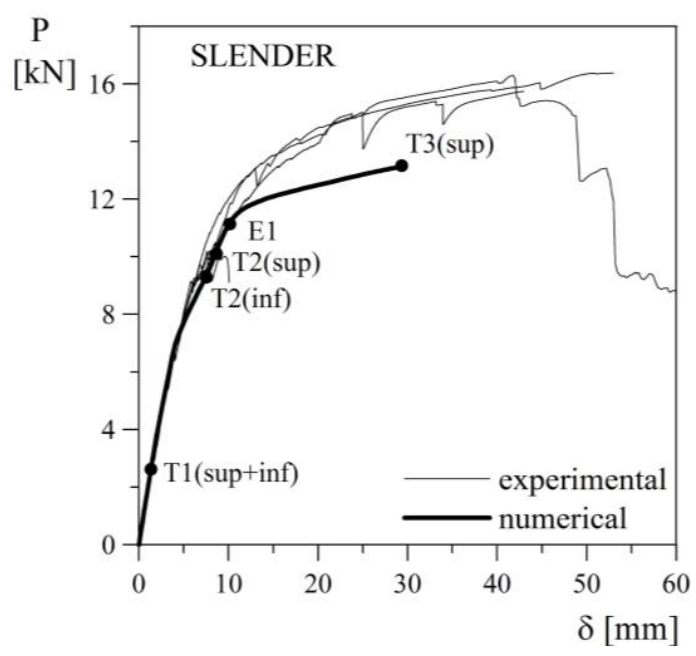

Fig. 13 FEM results - vertical load vs. displacement curves for slender sandwich beam. 
As done for deep sandwich beam, the load $(P)$ versus vertical displacement $(\delta)$ numerical curve is compared to the experimental results, achieving quite a good agreement in terms of global response (Figure 13). A good superposition is achieved in the initial linear phase, while the non-linear branch of the numerical response is lower than that of the experimental curves; moreover, the model is not able to predict the ductility exploited by the beams. Looking at the relevant points related to the material constitutive laws highlighted on the numerical response, it is possible to note that after reaching point $E 1$ the global response becomes highly non-linear. As observed for the deep sandwich, the beam behaves as a partially composite sandwich (Figure 14).
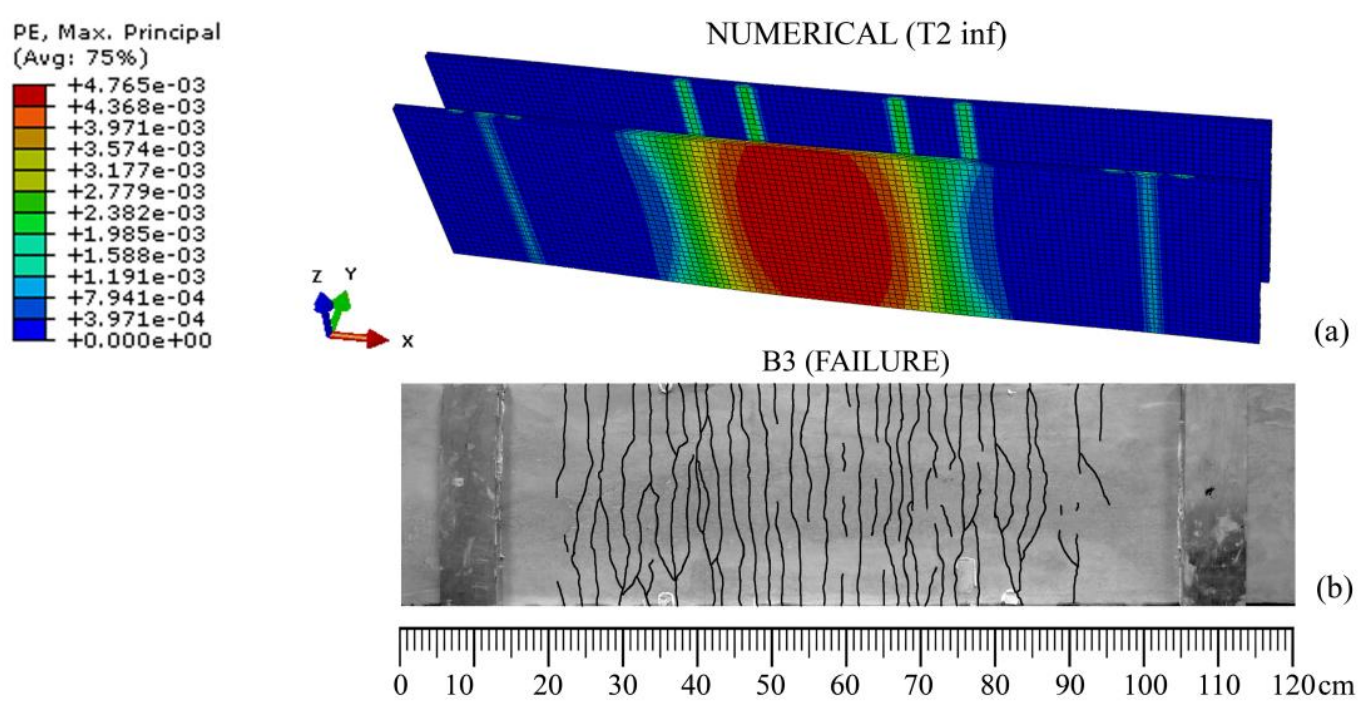

Fig. 14 FEM model of slender sandwich beam - multi-cracking of both TRC layers: maximum principal plastic strain at point T2inf (a) and picture of the intrados of specimen B3 at failure (b). [COLOR PRINT]

The yielding of a compressed strut in the EPS layer, which in the tests caused the tensile crack and the sudden failure of the specimens (Figure 15(c)), is clearly shown in Figure 15 (a) and (b) by means of maximum principal plastic strains and stresses. Again, the numerical analysis stops because of the incompatibility of the deformations of EPS and TRC at the interface caused by the perfect bond assumption, hence it is not possible to model the large ductility experienced by the specimens. 

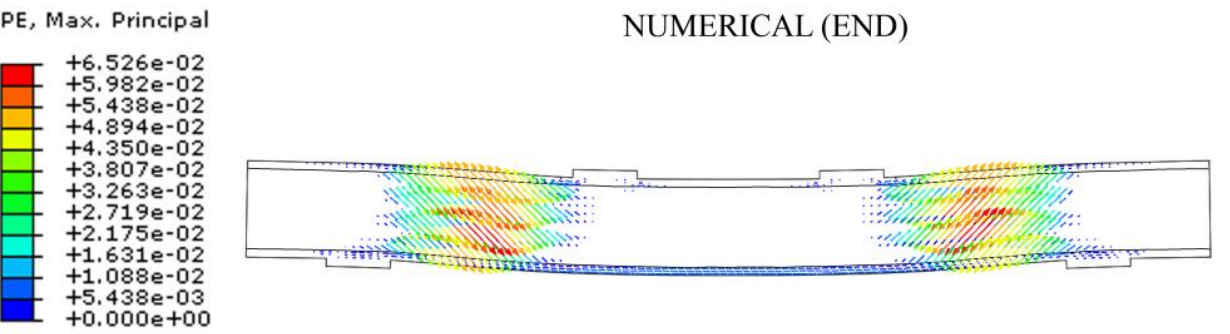

S, Max. Principal

(a)
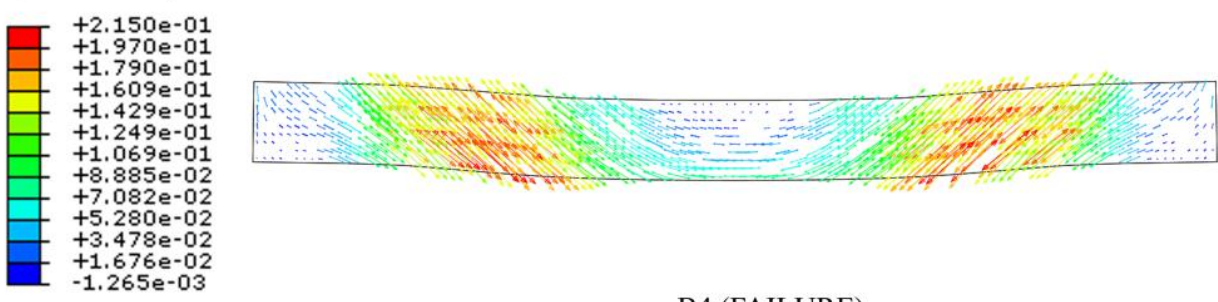

(b)

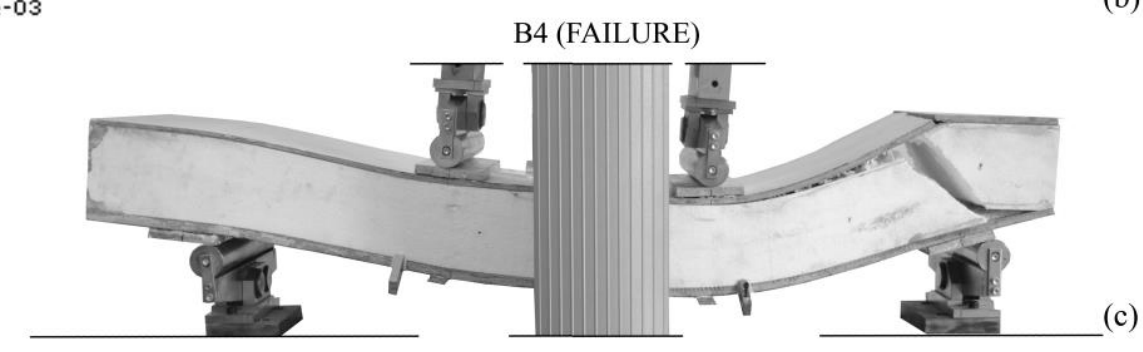

Fig. 15 FEM model of slender sandwich beam - EPS failure: (a) maximum principal plastic strain and (b) maximum principal stresses in the EPS layer at the end of the numerical analysis; (c) specimen B4 at failure. [COLOR PRINT]

\section{Comparison of results}

The results of the analytical and numerical analysis are summarised in Figure 16. In the same figure, the experimental curves are plotted as a reference (grey shadow).

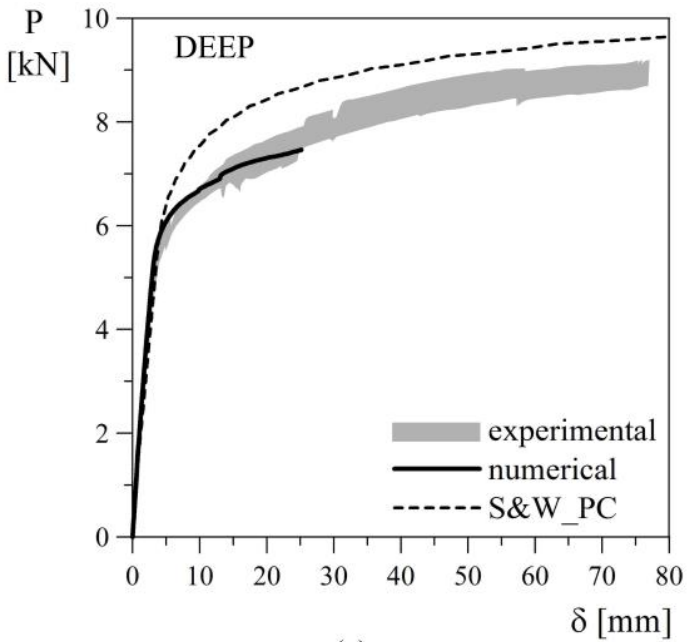

(a)

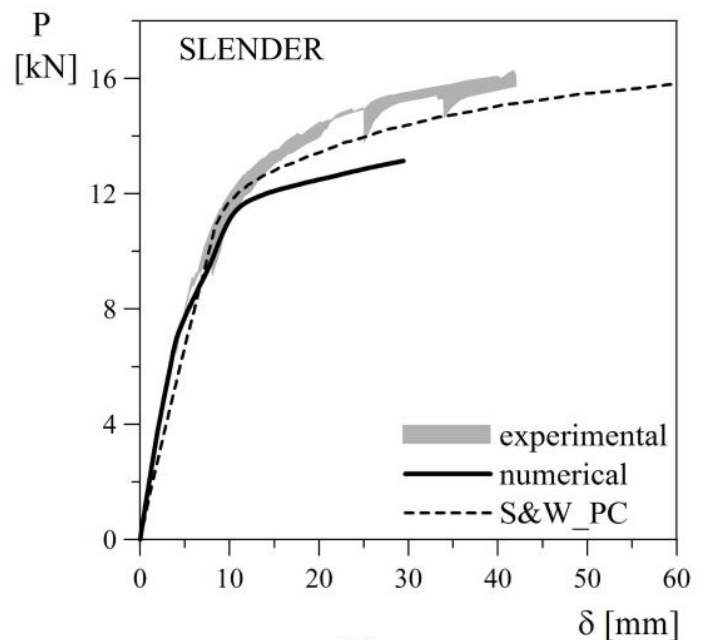

(b)

Fig. 16 Comparison of experimental, analytical and numerical results for deep (a) and slender (b) sandwich beams. 
Concerning the analytical response (dashed lines), it provides a reliable prediction of the results; in case of deep beam the model overestimates the maximum load of about 10\% (Figure 16(a)), while for slender sandwich beam the solution is conservative (Figure 16(b)). As already discussed, the model is not able to predict the specimen failure as no failure criterion is introduced.

Looking at the numerical results (solid bolt lines), it is possible to state that the response well catches the experimental results especially in the case of deep specimens (Figure 16(a)), while in the case of slender sandwich beam an underestimation of the real behaviour in the plastic branch of about 15\% can be observed (Figure 16(b)). In both deep and slender specimens, the ductility cannot be regarded as reliable because analysis stopped due to the large distortion of the elements at EPS-TRC interface.

\section{Conclusions}

The results of the analytical and numerical analysis suggest some interesting conclusions.

In particular, concerning the analytical modelling, the results of the analysis confirm the reliability of the assumptions imposed in order to evaluate the global response of the sandwich solution. For slender sandwich beam the analytical solution is conservative, while in case of deep beam the model overestimates the maximum load of about $10 \%$. The results obtained through the analytical model show how the fabric position within the external layers has a low influence on the global sandwich response, which is mainly governed by the non-linear behaviour of EPS and by the membrane and bending behaviour of TRC.

Concerning the FE analysis, the choice of modelling TRC as a homogeneous material is reliable if the aim is to determine the global response of the solution; local information is not captured. The Crushable Foam model, with initial domain parameters identified from compressive, tensile and shear tests on EPS specimens, allows to properly predict the behaviour of EPS in compression and consequently to model the strut in the sandwich beams.

For both deep and slender sandwich beams, the perfect bond assumption is reliable in the initial part of the analysis and also when the sandwich behaviour becomes highly non-linear. However, this assumption does not allow to simulate the high ductility experienced by the specimens due to the large deformations that arise at TRC/EPS interface, thus creating convergence problems. The FEM model adequately predicts experimental results both in terms of global response and deformation modes. In the case of slender sandwich beam the numerical response is conservative, with an underestimation of load in the plastic branch of about $15 \%$ with respect to the real behaviour.

\section{Acknowledgments}

The authors would like to thank Gavazzi company for supplying the AR glass fabric. The research was financially supported by the European "EASEE" project, Grant Agreement No. 285540, Thematic Priority: EeB.NMP.2011-3 - 
Energy saving technologies for buildings envelope retrofitting, Starting date of project: $1^{\text {st }}$ of March, 2012, Duration: 48 months.

\section{References}

[1] Vinson, J. (1999) The Behavior of Sandwich Structures of Isotropic and Composite Materials. Technomic Publishing Company.

[2] Davies, J. (2001) Lightweight Sandwich Construction. Wiley-Blackwell.

[3] Einea, A., Salmon, D. C., Fogarasi, G. J., Culp, T. D., and Tadros, M. K. (1991) State-of-the-art of Precast Concrete Sandwich Panels. PCI Journal, 36(6), 78-92.

[4] Salmon, D., Einea, A., Tadros, M., and Culp, T. (1997) Full scale testing of precast concrete sandwich panels. ACI Structural Journal, 94(4), 354-362.

[5] Benayoune, A., Samad, A., Trikha, D., Ali, A., and Ellinna, S. (2008). Flexural behaviour of pre-cast concrete sandwich composite panel - Experimental and theoretical investigations. Construction and Building Materials, 22(4), 580-592.

[6] Naito, C., Hoemann, J., Beacraft, M., and Bewick, B. (2011) Performance and characterization of shear ties for use in insulated precast concrete sandwich wall panels. Journal of Structural Engineering, 138(1), 52-61.

[7] Hegger, J., and Horstmann, M. (2009) Light-weight TRC sandwich building envelopes. Excellence in Concrete Construction through Innovation, 187-194.

[8] Shams, A., Horstmann, M., and Hegger, J. (2014) Experimental investigations on Textile-Reinforced Concrete (TRC) sandwich sections. Composite Structures, 118, 643-653.

[9] Colombo, M., di Prisco, M., and Zecca, C. (2008) On the coupling of soft materials with thin layers of Glass Fibre Reinforced mortar. CCC 2008 - Challenges for Civil Construction.

[10] Dey, V., Zani, G., Colombo, M., di Prisco, M. and Mobasher, B. (2015) Flexural impact response of textile-reinforced aerated concrete sandwich panels. Materials and Design, 86, 187-197.

[11] di Prisco, M., Ferrara, L., Lamperti, M., Lapolla, S., Magri, A., and Zani, G. (2012) Sustainable Roof Elements: A Proposal Offered by Cementitious Composites Technology. In M. N. Fardis (edited by), Innovative Materials and Techniques in Concrete Construction (p. 167-181). Springer Netherlands.

[12] di Prisco, M., and Zani, G. (2012) Experimental and numerical analysis of advanced cementitious composites for sustainable roof elements. Proceedings of the "Numerical modeling - Strategies for Sustainable Concrete Structures - Aix-en-Provance, France".

[13] Ferrara, L., Colombo, M., di Prisco, M., and Zecca, C. (2008) Sandwich panels with Glass Fiber Reinforced surfaces for affordable housing. CCC 2008 - Challenges for Civil Construction.

[14] Müller, F., Kohlmeyer, C., and Schnell, J. (2012) Load-Bearing Behaviour of Sandwich Strips with XPS-Core and Reinforced HPC-Facings. Proceedings of Hipermat 2012 - 3rd International Symposium on UHPC and Nanotechnology for High Performance Construction Materials (p. 781-788). Kassel University Press.

[15] Stamm, K., and Witte, H. (1974). Sandwichkonstruktionen: Berechnung, Fertigung, Ausfiihrung. WienNew York: SpringerVerlag. [16] Plantema, F. J. (1966) Sandwich construction: the bending and buckling of sandwich beams, plates and shells. Wiley.

[17] Shams, A., Hegger, J., and Horstmann, M. (2014) An analytical model for sandwich panels made of Textile-Reinforced Concrete. Construction and Building Materials, 64, 451-459.

[18] Hegger, J., Horstmann, M., and Shams, A. (2011) Load-Carrying Behaviour of Sandwich Panels at Ultimate Limit State. Proceedings of the fib Symposium Prague 2011 - Concrete Engineering for Excellence and Efficiency.

[19] Larrinaga, P., Chastre, C., Biscaia, H. C., and San-Josè, J. T. (2014) Experimental and numerical modeling of basalt textile reinforced mortar behavior under uniaxial tensile stress. Materials \& Design, 55, 66-74.

[20] Miccoli, L., Fontana, P., Johansson, G., Zandi, K., Williams Portal, N., and Müller, U. (2015) Numerical modelling of UHPC and TRC sandwich elements for building envelopes. Proceedings of the "IABSE Conference - Structural Engineering: Providing Solutions to Global Challenges", 195-203. Geneva, Switzerland.

[21] Larbi, A. S., Agbossou, A., and Hamelin, P. (2013). Experimental and numerical investigations about textile-reinforced concrete and hybrid solutions for repairing and/or strengthening reinforced concrete beams. Composite Structures, 99, 152-162. 
[22]Masso-Moreu, Y., and Mills, N. (2004) Rapid hydrostatic compression of low-density polymeric foams. Polymer Testing, 23(3), 313-322.

[23] Ozturk, U. E., and Anlas, G. (2011) Finite element analysis of expanded polystyrene foam under multiple compressive loading and unloading. Materials \& Design, 32(2), 773-780.

[24] EASEE. (2012-2016) European Project: Envelope Approach to improve Sustainability and Energy efficiency in Existing multistorey multi-owner residential buildings (www.easee-project.eu).

[25] Colombo, I.G., Colombo, M., and di Prisco, M. (2016). TRC multilayer precast façade panel: structural behavior in freezingthawing condition. Proceedings of the II International Conference on Concrete Sustainability ICCS16.

[26] Colombo, I.G., Colombo, M., and Di Prisco, M. (2015) Bending behaviour of Textile Reinforced Concrete sandwich beams. Construction and Building Materials, 95, 675-685.

[27] EN 196-1 (2005) Methods of testing cement - Part 1: Determination of strength.

[28]Colombo, I.G., Magri, A., Zani, G., Colombo, M., and Di Prisco, M. (2013) Textile Reinforced Concrete: Experimental investigation on design parameters. Materials and Structures, 46(11), 1933-1951.

[29] EN 13163 (2009) Thermal insulation products for buildings. Factory made products of expanded polystyrene (EPS) - Specification.

[31] Brameshuber, W., Brockmann, T., Curbach, M., Meyer, C., Vilkner, G., Mobasher, B., ... Wastiels, J. (2006). Textile Reinforced Concrete - State-of-the-art Report of RILEM Technical Committee 201-TRC. In W. Brameshuber (edited by). RILEM Publications.

[34] Gnip, I., Veyelis, S., Kersulis, V., and Vaitkus, S. (2007) Deformability and Strength of Expanded Polystyrene (EPS) under Short-

[35]Lee, J., and Fenves, G. (1998) Plastic-Damage Model for Cyclic Loading of Concrete Structures. Journal of Engineering Mechanics, 124(8), 892-900.

589 [36]Simulia (2011) Abaqus Analysis User's Manual.

590 [37]Lubliner, J., Oliver, J., Oller, S., and Onate, E. (1989) A Plastic-Damage Model for Concrete. International Journal of Solids and 591 Structures, 25, 299-329.

592 [38]Deshpande, V. S., and Flek, N. (2000) Isotropic Constitutive Model for Metallic Foams. Journal of the Mechanics and Physics of 